\title{
Does Educational Equality Increase Mobility? Exploiting Nineteenth-Century U.S. Compulsory Schooling Laws ${ }^{1}$
}

\author{
Emily Rauscher \\ University of Kansas
}

\begin{abstract}
Existing evidence of educational effects on intergenerational mobility is associational. This study employs early compulsory schooling laws to approach a causal estimate of the relationship between education and mobility in the context of a large-scale policy change. Using IPUMS Linked Representative Samples (linked census data), regression discontinuity models exploit state differences in the timing of compulsory schooling laws to estimate an intent-to-treat effect on intergenerational occupational mobility among white males. Despite increasing equality of attendance, results reveal that compulsory laws initially reduced relative mobility for the first few cohorts affected by the laws. Among later cohorts, who were required to attend the maximum years of school, mobility was similar to prelaw levels. School funding and other data suggest that structural lag could explain this nonlinear relationship. It seems, therefore, that educational expansion inadvertently reduced mobility through institutional inertia rather than elite efforts to maintain advantage.
\end{abstract}

\section{INTRODUCTION}

Historical studies of intergenerational mobility typically estimate the degree of relative mobility rather than its causes (e.g., Ferrie 2005; Xie and Killewald 2010). Those interested in factors affecting historical mobility

${ }^{1}$ This research was supported by a National Academy of Education/Spencer Foundation Dissertation Fellowship and an Institute for Education Sciences (IES) Predoctoral Fellowship. Many thanks to Dalton Conley, Florencia Torche, Richard Arum, Caroline

(C) 2016 by The University of Chicago. All rights reserved.

0002-9602/2016/12106-0002\$10.00 
generally focus on industrialization and find little evidence of a mobilityindustrialization relationship, despite its theoretical appeal (Sorokin 1959; Kaelble 1981, 1986; see van Leeuwen and Maas [2010] for a review). Industrialization involved a variety of large-scale changes. Perhaps the lack of evidence reflects an imprecise focus on industrialization, when it was actually a certain aspect of industrialization that influenced mobility.

Educational expansion was a central feature of industrialization, meeting the growing demand for skilled and socialized workers. At least since Horace Mann in the 19th century, education reformers and arguably even the public have perceived education as an equalizing institution that promotes equal opportunity through relative intergenerational mobility. In the late 1800 s, state compulsory schooling laws aimed to overcome different family backgrounds by mandating school attendance for all. Did early compulsory school attendance laws increase intergenerational occupational mobility? As this study will show and consistent with existing research (Rauscher 2014), the laws increased equality of school attendance by social background. However, the potential effect of this educational equality on mobility remains unclear for several reasons.

First, both historical and recent research suggests that, as one level of schooling expands or becomes more equal, elites may maintain their relative advantage by acquiring more or better quality schooling (Collins 1971; Raftery and Hout 1993; Lucas 2001; Parman 2011). Such unequal responses may leave intergenerational mobility unchanged or even lower than before the school reform. For example, Parman (2011) studied Iowa in the early 1900s and found that public school expansion was associated with lower income mobility.

Second, despite high-quality research, all evidence of the educationmobility relationship is associational (e.g., Blau and Duncan 1967; Hout 1988; Goldin 1999; Breen and Jonsson 2005). Education is a well-establishedand arguably the central - mediating factor between father's occupation and individual attainment (Blau and Duncan 1967; Featherman and Hauser 1978; Hout 1988, 1989). Breen (2010, p. 365) highlights an "underlying assumption ... that a weakening of the relationship between origins and educational attainment will lead to a weakening of the relationship between origins and destinations." However, the difficulties of intergenerational research have limited the opportunity to establish a causal relationship between education and intergenerational mobility.

Persell, and Jennifer Jennings, as well as ChangHwan Kim, John Rury, Lynn Davidman, anonymous reviewers, and members of the New York University IES Predoctoral Interdisciplinary Research Training program for helpful feedback. Direct correspondence to Emily Rauscher, University of Kansas, Department of Sociology, 1415 Jayhawk Boulevard, Lawrence, Kansas 66045. E-mail: emily.rauscher@ku.edu 
Causal evidence requires an exogenous influence on schooling to rule out claims that results are driven by unobserved characteristics (such as motivation or intelligence) of the individuals who choose to achieve more schooling. Causal effects of education in one generation are well established (e.g., on earnings and mortality; Angrist and Krueger 1991; LlerasMuney 2005). However, research has yet to identify the causal effect of education on intergenerational occupational mobility (Grawe 2008) and instead has typically relied on descriptive techniques (Cunha, Heckman, and Navarro 2006).

Third, we do not know under what contexts education mediates the link between origins and destinations. Status attainment research typically focuses on the mediating role of education in developed societies. In the late 1800s, as the United States experienced rapid industrialization, education may have had a different relationship with occupational mobility than it does today. Furthermore, large-scale policy changes can yield different outcomes than evidence from smaller-scale educational experiments would predict. While research typically studies educational effects using smallscale experiments, rare exceptions find that large-scale educational changes can yield different and unanticipated results (Angrist 1995; Torche 2005; Acemoglu and Johnson 2007; Acemoglu 2010). To fully understand effects of educational expansion, we must investigate it when schooling changed for a large number of people.

\section{DOES EDUCATIONAL EQUALITY INCREASE INTERGENERATIONAL MOBILITY?}

Specifically, did 19th-century state compulsory school attendance laws, which made school attendance more equal by father's occupation, increase relative intergenerational occupational mobility? ${ }^{2}$ Opportunities to investigate a causal relationship between education and intergenerational mo-

\footnotetext{
${ }^{2}$ While education may increase both absolute and relative occupational mobility, this article focuses on relative mobility. Mobility research has long distinguished between absolute and relative mobility (Featherman and Hauser 1978; Hout 1988). Absolute mobility is the change in occupational distribution. It measures how much intergenerational change in occupations is due to changes in the distribution. Relative mobility is the degree of occupational change between generations unexplained by distributional change. It measures social fluidity-the degree to which individual opportunity or occupational attainment is not associated with parent's occupation net of distributional changes (an imperfect measure because a portion of parent-child association could reflect inherited ability and household factors such as socialization; Jencks and Tach 2006). Education may increase absolute mobility through economic growth, raising occupational outcomes for everyone (Acemoglu and Angrist 2000; Cheung and Chan 2008; Hanushek and Woessmann 2009; Li and Huang 2009). However, as the distribution shifts up for everyone, relative mobility could remain the same or even decrease. Unless specified, mobility refers to relative mobility throughout this article.
} 
bility are rare given data demands. This study uniquely approaches a causal estimate of the relationship between education and intergenerational mobility. Exploiting state differences in the timing of compulsory school attendance laws and linked census data from 1850 to 1930 (with occupational information for father-son pairs), this study investigates the education-mobility relationship in a large-scale setting. At the turn of the century - an era with high industrialization and rapid educational expansion-did compulsory schooling laws, which increased equality of school attendance, reduce the importance of father's occupation for young white men's occupational attainment?

The next section provides historical background about 19th-century educational expansion and early compulsory schooling laws in the United States. Later sections offer theoretical and empirical background, information about data and methods, results, and a discussion including potential contemporary implications.

\section{HISTORICAL CONTEXT}

\section{9th-Century American Educational Expansion}

School attendance - and the education system in general - expanded throughout the 1800s, beginning in the Northeast and spreading to the West (Meyer et al. 1979). Explanations for postbellum educational expansionand the functions schools served-are still contested (Baker 1999) but largely fall into two categories. One, schools served the labor and socialization needs of capitalism, industrialization, and urbanization (Katz 1968; Bowles and Gintis 1976; Field 1976; Baker 1999). From this perspective, schools taught skills for life in an increasingly interdependent society and legitimated inequality, partly by teaching children their social place.

Two, educational expansion - in the United States and throughout the world-reflected nation-building efforts, specifically evangelical Protestant and Republican efforts in the United States (Meyer, Ramirez, and Soysal 1979, 1992). The middle and late 1800s witnessed unprecedented immigration, particularly from Ireland after the famine, and schools represented an assimilation tool to Americanize newcomers, assuage native fears of Catholicism, and teach civic identity to all (Carlson 1975; McAfee 1998). Furthermore, economic depressions during the late 1800s (including the Panic of 1873 and depressions in 1882-85 and 1893-96) threatened national unity and heightened class divisions. Education could help weld society back together. Related to nation building, others highlight the central role of the state in shaping and expanding the educational system (Archer 1979; Rubinson 1987; Walters 2000; Steffes 2012), possibly through compulsory schooling laws, for example. Aiding the expansion, the common school provided free education to all through local taxes and rapidly re- 
placed other forms of schooling in the North around the 1840s (Kaestle 1983).

In addition to these explanations, beliefs about the equalizing potential of education may have helped spur the expansion. Horace Mann-a 19th-century Massachusetts politician and education reformer-was a champion of the common school. Mann (1849, p. 59) called education "the great equalizer of the conditions of men" and believed it could promote American identity and access to the middle class. Thus, the belief that education promotes intergenerational mobility is not unique to today.

Compulsory school attendance laws were the legal arm of 19th-century educational expansion. For schools to achieve any of the stated goalswhether to socialize workers or equalize opportunity — students had to attend them. Higher wages for educated workers, individual interests, or values may have pulled some youth into school (Goldin and Katz 2008), but state policies such as compulsory school attendance laws may have pushed more reluctant (especially lower-class) youth.

\section{U.S. Compulsory School Attendance Laws}

Compulsory education laws in the United States preceded compulsory schooling or attendance laws by around 200 years. In both cases, Massachusetts led the way. In 1642, Massachusetts required that parents and masters be responsible for teaching their children and apprentices to read English and to understand religious principles and laws (U.S. Bureau of Education 1914). Five years later, the "old deluder Satan" act of 1647 required Massachusetts towns of at least 50 households to appoint a teacher and towns of at least 100 households to establish a grammar school.

Compulsory school attendance laws began in 1852, when Massachusetts required that all children between ages 8 and 14 attend school for at least 12 weeks. Beginning in the early 1800s, a hodgepodge of laws required varying lengths of schooling for children working in manufacturing or business. The compulsory schooling law was novel because it applied to all children (with exemptions for physical, mental, or economic inability), not just those employed in manufacturing. Noncompliance could be punished with a fine of up to $\$ 20$.

The first compulsory schooling laws of other states were remarkably similar to that of Massachusetts. The children affected were nearly always ages $8-14$. The punishment for noncompliance was generally monetary and, where information is available, the length of required attendance was consistently about 12 weeks. Many advantaged children attended school anyway, and private school remained an option (for elites or religious minorities). For the majority, however, compulsory attendance aimed to corral children from all backgrounds together into a "common school" for 
instruction from a professional teacher. From 1852 to 1918, beginning with Massachusetts and finishing with Mississippi, each state passed a law requiring youth to attend school.

Existing studies of early compulsory schooling laws often find that they had little effect on school attendance (Landes and Solmon 1972; Edwards 1978; Goldin and Katz 2011). Others argue that only early compulsory schooling laws were ineffective or symbolic (Tyack 1976), while later changes to the compulsory laws in the beginning of the 20th century were successful (Katz 1976; Lleras-Muney 2005). This evidence of ineffective laws could reflect imperfect enforcement or exemptions allowed by the law (e.g., for physical, mental, or economic inability). However, a recent study by Puerta (2009) contradicts such findings. Using more sophisticated techniques (county-level difference-in-difference), Puerta finds that compulsory laws increased absolute attendance rates by about $7 \%$.

Most important, little research investigates heterogeneous effects by class, which may explain previous null findings. That is, research has rarely investigated whether early compulsory laws increased equality of attendance (Rauscher 2014). Discussions of compulsory education around the time suggest that it should have equalized school attendance. For example, in discussing the various laws affecting children of New England, John Perrin (1896, p. 71) writes: "As the various statutes now stand they constitute a species of class legislation." He describes compulsory and truancy laws as "remedial": "Its design is the correction of existing evils, and the conversion of the youth belonging to what is known as the "dangerous and perishing classes' into good citizens” (1896, p. 71). In a speech supporting compulsory schooling, Ernest Carroll Moore (1902, who later became superintendent of Los Angeles schools) similarly identified children of immigrants, deviant or neglectful parents, and the poor as the necessary targets of compulsory schooling laws, claiming that these children do not or cannot appreciate the value of education. A legal history of compulsory attendance laws similarly suggests that they were aimed primarily at poor or lower-class children (Kotin and Aikman 1980). Despite the potential for exemptions because of economic inability, therefore, the laws aimed to increase attendance among lower-class children. Because they targeted poor children, who were least likely to attend, compulsory schooling laws should make school attendance more equal by class.

\section{THEORETICAL AND EMPIRICAL BACKGROUND}

If compulsory laws increased equality of school attendance by father's occupation, status attainment and industrialization theories would expect these laws to make occupational opportunity more equal as well. Both theories paint education as central to intergenerational mobility (Blau and 
Duncan 1967; Treiman 1970). ${ }^{3}$ At the individual level, Blau and Duncan (1967) famously find that educational attainment plays the largest role in occupational attainment. It mediates the link between origins (father's occupation and education) and occupational destination, but it also has an important independent effect, suggesting that (for white men) the U.S. occupational system is primarily based on universalistic criteria through education. This model has been complicated and expanded (e.g., Sewell, Haller, and Portes 1969), but the centrality of education has remained despite the model's basis on associational evidence. At the societal level, industrialization theory similarly expects mass education to increase mobility by making skills and cultural values more similar by class and encouraging employers to rely on educational achievement to remain competitive (Treiman 1970). As with attainment, studies of the industrialization thesis are associational, not causal (Grusky 1983).

While education is clearly associated with the link between origin and destination, other factors, such as individual motivation or economic growth of a society, may drive the education-mobility relationship. Furthermore, large-scale increases in education could yield different effects. Educational expansion could generate credential inflation without improving mobility (Perkinson 1968; Berg 1971; Collins 1971; Milner 1972; Boudon 1974). Empirical evidence from Ireland, Chile, and the United Kingdom indicates that expansion can increase class inequality at certain education levels (Raftery and Hout 1993; Torche 2005; Paterson and Iannelli 2007). Multiple theories explain why expanding access to schooling might decrease mobility. Collins's (1971) interpretation of conflict theory, for example, would expect elites to attain more schooling if one level became widespread. Similarly, as one level becomes more equal, differences in the quantity or quality of schooling may become more important (Raftery and Hout 1993; Lucas 2001). In terms of mobility, while education may increase intergenerational opportunity in other areas (Oreopoulos, Page, and Stevens 2006; Attewell and Lavin 2007), its effect on occupational mobility could be different. Parman (2011) and Grawe (2010) find that improvements in public school quality are associated with declines in intergenerational income mobility, possibly because higher-income families take more advantage of betterquality schools. From these perspectives, compulsory schooling is likely either to have no effect or to decrease occupational mobility because elites

\footnotetext{
${ }^{3}$ Human capital and social network theories (Becker 1964; Granovetter 1973) suggest that education could either weaken the effect of class background on attainment through more equal access to valuable skills and social ties or mediate the origin-destination relationship (Becker and Tomes 1994). In the 19th century, compulsory education could also take youth away from apprenticeships or employment that provided valuable human or social capital. If on-the-job training was more valuable than schooling in the 1800 s, compulsory schooling could reduce mobility despite adding human capital. Given this ambiguity, other theories are more useful here.
} 
will work to maintain their relative advantage in quantity or quality of education.

Alternatively, structural lag (Riley et al. 1994) expects increased school attendance to reduce mobility - at least initially. Structural lag, developed in the context of the mismatch between cohort size or characteristics and institutional change, suggests that institutions change more slowly than the people in them (Riley et al. 1994). An example occurs when a cohort is larger or more diverse than the roles allotted to it. Applied to compulsory schooling, structural lag suggests that the school system may be slow to adapt to the increase in number and diversity of students. Because of the delayed institutional response, school performance and learning should initially decline. For example, as truants and other new types of students attend school for the first time, they could disrupt everyone's learning through poor discipline, infrequent attendance, or classroom crowding. These declines in quality would affect any school gaining new students but would be concentrated in schools attended by lower-class children, who were targeted by the laws. Thus, even without elites working to maintain advantage, greater attendance of lower-class youth would perversely decrease class equality in the quality of schooling received. If school systems eventually responded, however, we would see a nonlinear pattern. In other words, mobility could initially decrease after the compulsory laws and then increase once institutions responded and adapted to the policy change. Evidence supporting this theory would include a delayed increase in school funding or teacher-to-student ratio after the compulsory law, suggesting that the system was slow to respond but eventually accommodated more students who were less prepared for school.

A growing body of research investigates the effects of more recent changes to compulsory schooling laws, including extensions of the compulsory schooling age (Lochner and Moretti 2004; Lleras-Muney 2005; Oreopoulos et al. 2006; see Brunello, Fort, and Weber [2009] for a review). Evidence consistently suggests that these extensions improve a variety of outcomes among the affected youth, including years of schooling and labor market outcomes (Oreopoulos 2006; Brunello et al. 2009). Moreover, the youth affected by these changes in compulsory schooling laws tend to be from lower-class backgrounds, suggesting that extended compulsory schooling increases intergenerational mobility.

The structural lag theory posits a key potential difference between effects of the first compulsory school attendance laws (studied here) and later extensions of the compulsory schooling age: effects on children who would have attended regardless of the legal change. These youth, referred to as "always takers" by statisticians developing causal inference techniques (Angrist, Imbens, and Rubin 1996, p. 448), would attend school even without 
the law, while "compliers" would change their behavior because of the legal change. With more recent changes to compulsory laws, educational institutions were adequately equipped to enroll more students for a longer period of time. At the time of the initial compulsory laws, however, schools may have been unprepared to absorb a sudden influx of new students who had never attended school. Moreover, because the laws aimed to increase attendance among lower-class youth, schools in lower-class neighborhoods should have experienced greater increases in enrollment with the laws than schools in upper-class areas. Structural lag theory suggests, therefore, that early compulsory schooling laws may have affected "always takers" differently by class. Lower-class youth who would have attended school anyway could be negatively affected by the compulsory law if it reduced the quality of schooling received because of the influx of new students. In contrast, higher-class youth who would have attended anyway would remain largely unaffected by the compulsory law, similar to the "always takers" in research on more recent changes to compulsory laws.

As Hong and Raudenbush (2006) note, an influx of compliers can change the experiences of always takers. Thus, despite convincing evidence that more recent extensions of compulsory schooling laws improve outcomes among lower-class youth (Oreopoulos 2006; Brunello et al. 2009), and should therefore increase intergenerational mobility, effects of the early compulsory laws studied here could yield different results by changing the counterfactual comparison group. That is, research on more recent compulsory changes compares those affected by extended compulsory schooling laws to a group who (at least based on stable unit treatment value assumptions) should have remained largely unaffected by the extended law. With the early laws studied here, however, structural lag theory suggests that those induced to attend by the law will be compared to a group whose schooling may have been disrupted by the law, and this disruption was unequally distributed by class.

\section{HYPOTHESES}

Hypothesis 1.-According to status attainment theory and the industrialization thesis, compulsory education should increase relative mobility. Compared to otherwise similar individuals, the occupation of those required to attend school should depend less on their father's occupation.

Нуротнеsis 2.-According to conflict theory, compulsory education should have either no effect or decrease relative mobility.

Нyротнеsis 3.-Structural lag expects a nonlinear effect, with mobility initially decreasing after a compulsory law and then increasing again after the school system adapted to the change. 
American Journal of Sociology

DATA

Recently released linked census data allow two observations of the same person (not possible with regular census data), providing both occupational background and outcome data. Integrated Public Use Microdata Series (IPUMS) Linked Representative Samples include individuals in the 1850-1930 censuses linked to the complete 1880 census (Ruggles et al. 2010; for a description, see Ruggles [2011]). The linking yields samples from seven pairs of censuses, which are pooled here: 1850-80, 1860-80, 1870-80, 1880-1900, 1880-1910, 1880-1920, and 1880-1930. At the first census observation, I gathered father's occupation and other background data for those who were children living in their father's household. Following these children to the second census observation period, I observed their own occupational attainment as adults. Figure 1 illustrates the data structure. All observations are linked to the 1880 census because that is the only $100 \%$ census. Therefore, the linked data include children in 1850, 1860, or 1870 , who later reappear as adults in 1880. Similarly, the data include children in 1880, who later reappear as adults in the 1900, 1910, 1920, or 1930 census. As a hypothetical example, imagine that we observe Joe Green at age 10 in the 1880 census, along with information about his social origins, including his father's occupation. Twenty years later, the 1900 census includes occupational information about Joe Green, now an adult (age 30).

I limit the sample to linked white boys who were under age 14 and either a child, grandchild, or nephew of the household head in the first census. The sample also excludes anyone younger than age 17 by the second census. This could give a relatively young occupational outcome measure for some individuals. However, adulthood and employment occurred earlier at the turn of the century, and age controls help address early outcome measurement. I limit analysis to white men because status attainment theory expects education to boost their occupational opportunity the most (because of discrimination facing women and minorities). Studying the effect on white men stacks the odds in favor of finding evidence to support status attainment or industrialization arguments and would make alternative results more surprising. ${ }^{5}$ Individuals from families who immigrated

\footnotetext{
${ }^{4}$ The 1890 census was destroyed by fire in 1921 and could not be linked. The missing 1890 census does not invalidate the study because it is missing for everyone, not just those required to attend or not required to attend school. If the 1890 census were available it would not substantially increase the sample size for this study. Individuals would only be 10 years older in 1890 than they were at the first observation in 1880 , so only a select group would be old enough to count as adults. The lack of the 1890 census may in fact yield a better estimate of mobility because individuals are older, on average, for their adult occupation measure.

${ }^{5}$ Furthermore, women who changed their last name could not be linked, leaving a nonrepresentative sample. Record quality for nonwhites is most likely poor and dependent on region-particularly prior to 1870 , when slaves were not even included in the census.
} 


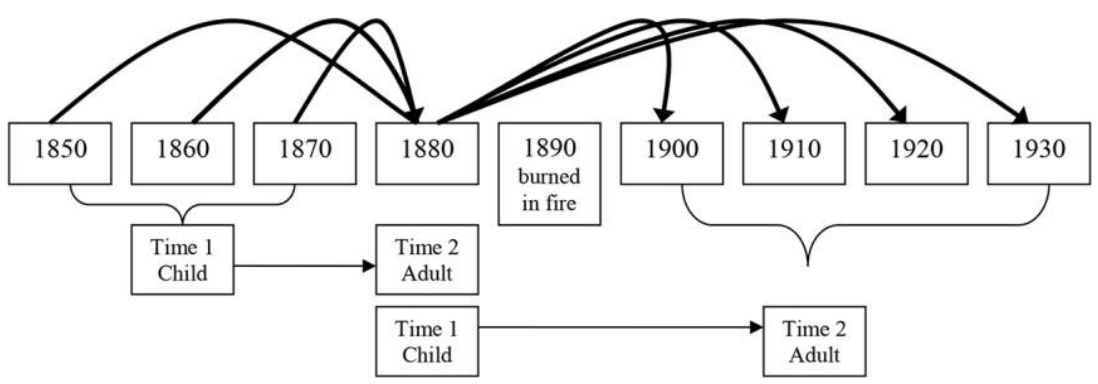

FIG. 1.-IPUMS Linked Representative Samples data structure. Children in the 1850, 1860 , and 1870 censuses are linked to their record in the $100 \% 1880$ census. Children in the 1880 census are linked to their record in the 1900,1910,1920, or 1930 censuses. This data structure allows two observations of the same individual-once as a child in their father's household and later as an adult. Observations are weighted to correct for unequal probability of linking.

after 1880 do not appear in the linked data set. The main analysis is limited to native white men but includes foreign-born individuals who were younger than age eight in the first census (i.e., spent their school-age years in the United States). ${ }^{6}$ Children in states that made school compulsory after 1890 are excluded to ensure statistical support in each state and because late-adopting states are overwhelmingly in the South, which may have important mobility differences. The youngest cohort in the linked data was born in 1880, so no individuals in late-adopting states were required to attend any years of school. Without statistical support (i.e., some children required to attend school and some not required), late-adopting statesincluding all states in the South-are excluded, and results cannot generalize to those areas.

One potential concern is validity of the linked data. IPUMS took precautions and created weights (used throughout this analysis) to correct for bias in linking and to ensure that the samples represent the population who survived between census years. ${ }^{7}$ Furthermore, the emphasis here is on internal, not external, validity. Comparison of those who happened to be school age at the time of the law versus those who narrowly missed being required to attend suggests that - because linking does not differ systematically by required schooling - the data are valid for this analysis. ${ }^{8}$

\footnotetext{
${ }^{6}$ Sensitivity analyses excluding all foreign-born individuals do not change results.

${ }^{7}$ IPUMS linked individuals on the basis of birth year, place of birth, first name, last name, and race. Exact matches were required for place of birth and race, but age and name were allowed to vary slightly. The linking strategy purposely ignored coresidents and place of residence to avoid overrepresenting nonmovers and those who live with family members. See http://usa.ipums.org/usa/linked_data_samples.shtml for more information. A comparison of linked and regular census data is available upon request.

${ }^{8}$ Historians raise concerns about the quality of 19 th-century census data, particularly the 1870 census (Steckel 1991). However, the greatest concern was about undercounting
} 
American Journal of Sociology

\section{MEASURES}

Occupation

IPUMS provides socioeconomic index (SEI) and occupational income scores standardized to 1950 for all of the linked census years. SEI score, sometimes considered occupational status, is based on the median income and educational attainment associated with each occupation among men in $1950 .{ }^{9}$ Occupational income score measures the median income of those in the occupation in 1950. The main analysis uses SEI scores, but occupational income scores yield similar results. ${ }^{10}$ Although most research studies effects of education on earnings, Hauser (1998) suggests that occupational status stabilizes relatively early in life and is less volatile so may provide a better measure of intergenerational mobility.

There were many changes in occupational distribution and classification from the late 1800 s to 1950 with industrialization and Taylorism (see, e.g., Conk [1978] on classification changes), but standardized scales are essential for this analysis because they allow meaningful intergenerational comparisons across multiple census years. Changes in the average income or status of occupations over time that are not captured in the standardized 1950 scores would add error to the measurement. However, this analysis is interested in how intergenerational occupational association changed with the compulsory laws. Therefore, the income or status of occupations would have to change systematically with compulsory assignment in order to threaten internal validity. This would require, for example, that - as opposed to simply changing over time-when the individuals in the sample reached adulthood, the SEI of an occupation (e.g., clerk or salesman) would have to have changed more for those required to attend school compared to those not required to attend. Such a scenario seems unlikely if not impossible, given that individuals in the sample are all within a narrow range of the law and occupational characteristics are defined by the education and income of all individuals with that job. Nevertheless, to increase compa-

of blacks in the South, neither of which are included here. Sensitivity analyses excluding each census individually yield similar results. Furthermore, unless census errors systematically differ by compulsory assignment, they will not threaten this analysis because I am concerned with how measures changed with the compulsory laws, not raw measurements. ${ }^{9}$ Because SEI is partly based on educational attainment, predicting SEI score may overestimate the effect of education on mobility. However, as Pascarella and Terenzini (2005) point out, even when using a status measure that incorporates education, the relationship between education and occupational status is not clear.

${ }^{10}$ Research distinguishes various measures of social standing, particularly earnings and occupational scores (Bjorklund and Jantti 2000; Beller and Hout 2006; Torche 2011). Occupational income score is the closest proxy for earnings and could show a different mobility pattern than status score (if education increased income mobility more than status mobility, for example). 
TABLE 1

Year of First Compulsory Education Law by State

\begin{tabular}{|c|c|}
\hline State & Compulsory School Year \\
\hline$\ldots \ldots \ldots \ldots \ldots \ldots \ldots \ldots \ldots$ & 1852 \\
\hline District of Columbia $\ldots \ldots \ldots \ldots \ldots \ldots \ldots \ldots$ & 1864 \\
\hline Vermont $\ldots \ldots \ldots \ldots \ldots \ldots \ldots \ldots \ldots \ldots \ldots$ & 1867 \\
\hline Michigan, New Hampshire, Washington . . . . . . . . . . & 1871 \\
\hline Connecticut, New Mexico $\ldots \ldots \ldots \ldots \ldots \ldots \ldots \ldots$ & 1872 \\
\hline Nevada $\ldots \ldots \ldots \ldots \ldots \ldots \ldots \ldots \ldots \ldots$ & 1873 \\
\hline California, Kansas, New York $\ldots \ldots \ldots \ldots \ldots \ldots \ldots$ & 1874 \\
\hline Maine, New Jersey $\ldots \ldots \ldots \ldots \ldots \ldots \ldots \ldots$ & 1875 \\
\hline Wyoming $\ldots \ldots \ldots \ldots \ldots \ldots \ldots \ldots \ldots$ & 1876 \\
\hline 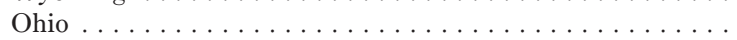 & 1877 \\
\hline Wisconsin $\ldots \ldots \ldots \ldots \ldots \ldots \ldots \ldots \ldots \ldots \ldots \ldots$ & 1879 \\
\hline Illinois, Montana, North/South Dakota, Rhode Island . . . . . & 1883 \\
\hline Minnesota $\ldots \ldots \ldots \ldots \ldots \ldots \ldots \ldots \ldots \ldots \ldots$ & 1885 \\
\hline Nebraska, Idaho $\ldots \ldots \ldots \ldots \ldots \ldots \ldots \ldots \ldots$ & 1887 \\
\hline Colorado, Oregon $\ldots \ldots \ldots \ldots \ldots \ldots \ldots \ldots$ & 1889 \\
\hline Utah $\ldots \ldots \ldots \ldots \ldots \ldots \ldots \ldots \ldots \ldots \ldots$ & 1890 \\
\hline 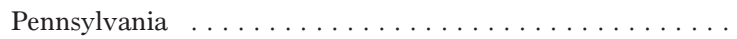 & 1895 \\
\hline Hawaii, Kentucky $\ldots \ldots \ldots \ldots \ldots \ldots \ldots \ldots \ldots$ & 1896 \\
\hline Indiana, West Virginia $\ldots \ldots \ldots \ldots \ldots \ldots$ & 1897 \\
\hline Arizona $\ldots \ldots \ldots \ldots \ldots \ldots \ldots \ldots \ldots \ldots \ldots$ & 1899 \\
\hline 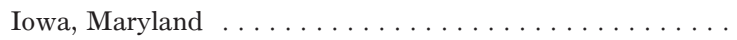 & 1902 \\
\hline Missouri, Tennessee $\ldots \ldots \ldots \ldots \ldots \ldots \ldots \ldots$ & 1905 \\
\hline Delaware, North Carolina, Oklahoma . . . . . . . . . . . & 1907 \\
\hline Virginia $\ldots \ldots \ldots \ldots \ldots \ldots \ldots \ldots \ldots \ldots$ & 1908 \\
\hline 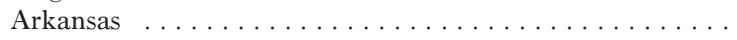 & 1909 \\
\hline Louisiana $\ldots \ldots \ldots \ldots \ldots \ldots \ldots \ldots \ldots \ldots$ & 1910 \\
\hline Alabama, Florida, South Carolina, Texas $\ldots \ldots \ldots \ldots$ & 1915 \\
\hline Georgia $\ldots \ldots \ldots \ldots \ldots \ldots \ldots \ldots \ldots \ldots \ldots$ & 1916 \\
\hline Mississippi & 1918 \\
\hline Alaska .................. & 1929 \\
\hline
\end{tabular}

NotE.-Data are from the U.S. Bureau of Education (1914, p. 10); U.S. Bureau of the Census (1924, p. 22).

rability with existing research (e.g., Featherman and Hauser 1978; Hout 1984; Hout 1989) and address concerns about continuous measures of occupational standing, supplementary analyses use occupational categories and yield similar results. See the appendix for details about the categorical measure of occupation, methods, and results.

\section{Compulsory Assignment Indicator}

State year of compulsory education, shown in table 1, is gathered from the U.S. Bureau of Education (1914, p. 10). ${ }^{11}$ Combining state of residence

${ }^{11}$ Dates after 1914 are from the 1920 U.S. Census (1924, table 5, pp. 22-23), confirmed by Goldin and Katz (2008) and Steinhilber and Sokolowski (1966, p. 3). There is general 
as a child, year of compulsory education law, ages at which the state law required attendance, and birth year, a dummy variable indicates whether an individual was ever school age after the law passed. In most states, compulsory laws required attendance for children ages 8-14 (Steinhilber and Sokolowski 1966), but a few states required attendance until age 15 (Maine, Rhode Island, Wisconsin) or age 16 (Connecticut, Minnesota, New Hampshire, Wyoming). In some cases, the law went into effect the year after it was passed. Even when the law went into effect the year it passed, many children would be a year older by the start of the next school year. Therefore, in creating the indicator for compulsory assignment, individuals who were the maximum age at which attendance was required when the law was passed are not considered part of the compulsory group. Everyone one year below the maximum age at the time of the law is included in the compulsory group because they were legally required to attend school for at least one school term. ${ }^{12}$

\section{Years of School Required}

To investigate nonlinear effects, I also create a measure of exposure to compulsory education. An individual just inside the age cutoff (14 in most states) would be required to attend school for one year. Those a year younger should attend for two years and so on. Although most states

agreement about the year of the first compulsory law in each state but slight disagreement about Kentucky (1896 vs. 1893) and Louisiana (1916 vs. 1910). Steinhilber and Sokolowski (1966, p. 3) list different dates for New Mexico (1891) and Texas (1873) than those provided by the Bureau of Education. Supplementary analyses assess sensitivity to assigning compulsory attendance based on these differences and do not change results. Note that disagreements about post-1890 dates are irrelevant for this study because those states are excluded to ensure statistical support.

${ }^{12}$ Another reason for choosing this cutoff, historians have noted, is that early compulsory laws were poorly enforced and employment was common and even encouraged among older youth around age 13 or 14 (Tyack 1974). Compulsory laws are therefore more likely to influence younger children under the maximum age required at the time of the law, when social norms and any child labor laws may have restricted employment. A few states (e.g., Ohio, Rhode Island, Colorado) passed child employment laws that specifically applied to children under age 14 in the same year as the attendance law. To address the possibility that any apparent effects of compulsory schooling laws depend on child labor laws, sensitivity analyses add controls for state child labor laws and individual exposure to child labor laws (child labor law dates are based on Loughran [1921]). The profusion of labor laws, which often applied to very specific groups during limited hours, makes it difficult to measure them accurately. The main analyses focus on compulsory schooling laws, but table A5 in the appendix provides results of sensitivity analyses that control for individual exposure to a child labor law through age 16 (based on state of residence as a child). Other sensitivity analyses (not shown) control for individual childhood years after a labor law and an indicator for whether an individual was ever covered by a child labor law. Results of these analyses are consistent with the main analyses. 
required attendance from ages 8 to 14 , the length was slightly different in other states. For example, Connecticut and Minnesota required attendance from age 8 to age 16, New Hampshire from 6 to 16, Rhode Island and Wisconsin from 7 to 15 , and Wyoming from 7 to 16 . To prevent individuals in these few states with different age requirements from being the only ones with higher ranges and driving the results, the range is capped from 0 to 9 for all states. Also, because states often expanded the required length of schooling after the first passage of the law, some students in states that initially required seven years were required to attend for up to nine years (e.g., Ohio, New Jersey). Thus, each individual in the sample is assigned a length of required school attendance based on year of birth, age at the time of the law, state of residence, and ages at which the first compulsory schooling law in each state required attendance.

Because I limit the sample to those 10 years on each side of the compulsory cutoff, years of school required also measures time since the law. In other words, it measures both how long each individual was legally required to attend school and how much time had passed since the law when that individual had to attend. Length of required attendance is therefore confounded with time since the law. The final step in this analysis offers some evidence to disentangle these concepts, but analysis using this measure cannot definitively identify which is the driving factor.

\section{School Attendance}

School attendance - available from 1850 to 1880 when the linked sample were children - is an indicator for whether an individual attended school in the last year. While census data provide a large sample, a limitation is that this is the only measure of education. Educational attainment was not recorded until the 1940 census. Nevertheless, the attendance indicator is not a bad measure given the flexibility of compulsory requirements. The laws generally required attendance for 12 weeks, only six of them consecutive. Intermittent attendance, permitted by the law, may not have been captured with other questions. ${ }^{13}$

A complication is that school attendance is only recorded at the year of the census. We therefore do not know whether an individual ever attended school, only if he attended within the last year. This requires limiting analysis of school attendance to those who were school age in the year prior to

\footnotetext{
${ }^{13}$ Daily school attendance was well below the number of students enrolled or registered. Lassonde (1996) notes about antebellum New Haven that only around two-thirds of those registered actually attended on a given day. If it were available, daily attendance could add more nuance to the investigation. Its absence, however, does not detract from the main analysis of the effect of the laws on mobility, which uses a reduced form approach to reduce bias.
} 
the census. All school attendance analyses therefore exclude those under age eight. This complication also requires using slightly altered compulsory measures in regressions predicting school attendance (but not adult occupation): individuals in states that have not yet passed the compulsory law, but who may be exposed to the law in the future, are coded zero years required and noncompulsory.

Finally, school attendance is not available for the $100 \% 1880$ census, which is used for the linked data. Only those in the smaller $1 \%$ or $10 \% 1880$ samples have this information. ${ }^{14}$ Literacy would be an alternate measure and would address questions of skills gained from schooling. However, literacy is not recorded for children in early censuses, is not available in the $100 \% 1880$ census, and is nearly universal (99.4\%) among adults in the linked sample, so it offers little variation. To overcome these limitations, I rely primarily on school attendance data in the regular (unlinked) census data. An intent-to-treat analysis of effects of compulsory laws on mobility allows inclusion of youth who are missing school attendance information or were not school age at the time of the census, bypassing the first-stage attendance measure.

\section{Additional Measures}

Other measures include age, birth cohort, rural residence, and state of residence. State-level measures included as controls are gathered from ICPSR (1970) Historical Census Data 1790-70, supplemented with information from original census tables and a compilation of statistical abstracts (U.S. Bureau of the Census 1975). Historical data from Behrens, Uggen, and Manza (2003) provide governor partisanship information. ${ }^{15}$

Table 2 provides descriptive statistics among all sons in the linked data sample, separately for those ever and never required to attend school. A few points are worth noting about table 2. First, mean father's occupational score is nearly always lower than son's, which suggests distributional changes in occupations between generations. Therefore, all regressions use standardized measures of individual and father's SEI scores.

Second, son's average age as an adult is younger than father's average age. This means that son's occupational outcome is measured at a younger

\footnotetext{
${ }^{14}$ In their FAQ (https://usa.ipums.org/usa/linked_data_samples_FAQ.shtml) about the linked data, IPUMS notes that school attendance information for 1880 was entered and released with the preliminary linked representative samples. The final version of the linked data (used here) only includes 1880 attendance information for those in the preliminary release. Thus, attendance is missing for $69 \%$ of the sample observed as schoolage children in 1880 .

${ }^{15}$ Many thanks to Jeff Manza, Christopher Uggen, and Angela Behrens for generously sharing their data.
} 
age than father's, on average. This is not ideal, because individuals may achieve a higher occupational outcome later in life and analyses could misestimate mobility. Estimates should not be biased as long as age at occupation is unrelated to compulsory assignment. However, age at adult observation is higher among those required to attend school, and compulsory education is required for younger cohorts in each state. To assess sensitivity to this potential age bias, I therefore replicate analyses when limiting the sample to individuals ages $30-64$ as adults. ${ }^{16}$ This reduces the difference in age at occupation (time 2 ) between the compulsory and noncompulsory groups to only two years and yields similar results (presented below).

Finally, the proportion noting that they attended school within the last year is significantly higher among those not required to attend school. This is puzzling but most likely reflects lack of complete school attendance information for those observed as children in the 1880 census. ${ }^{17}$ School attendance information is not missing at random with respect to census year of observation. Therefore, attendance data among those required to attend is more often from earlier census years, when overall attendance rates were lower. The nonrandom missing data most likely explain the low attendance rates in the compulsory group shown in table 2 . To address concerns about attendance information in the linked data, I show results predicting school attendance among individuals in 1850-80 regular census data. Table 3 shows descriptive statistics for school-age white boys in the regular 1850-80 censuses. Results of attendance analyses in the linked and regular data are consistent.

Tables 2 and 3 also include the correlation between father's SEI and school attendance. In the linked data, this correlation is 0.06 in the noncompulsory group and zero in the compulsory group. Among white boys

\footnotetext{
${ }^{16}$ Age bias is a concern in studies of earnings (e.g., Haider and Solon 2006) because earnings can change drastically over the lifespan. Based on data from the mid to late 20th century, occupation is less volatile and stabilizes relatively early in life (Hauser 1998), which suggests that age at occupation is less of a concern. Furthermore, men in the early 1900s may have achieved their permanent occupation at a younger age (given shorter life spans and average length of schooling). Nevertheless, the age 30-64 sample helps address concerns about age bias by excluding younger individuals who may or may not have already achieved their highest occupational status.

${ }^{17}$ See n. 14. Of the potential school-age cases in the linked data, $59 \%$ of those required to attend school are missing school attendance data, compared to only $26 \%$ of those not required to attend. Among cases missing attendance information, $82 \%$ were in the compulsory category. Aside from missing data, there are other potential explanations for the difference in attendance by compulsory assignment. For example, what people thought counted as school attendance could have changed with the law. Before the law, families or census takers may have counted attendance of even one day. After the law, however, reports may not count a child as attending school unless they met the legal compulsory requirements. Regardless of the explanation, however, of primary interest here is the relationship between school attendance and father's occupation- not raw attendance data.
} 


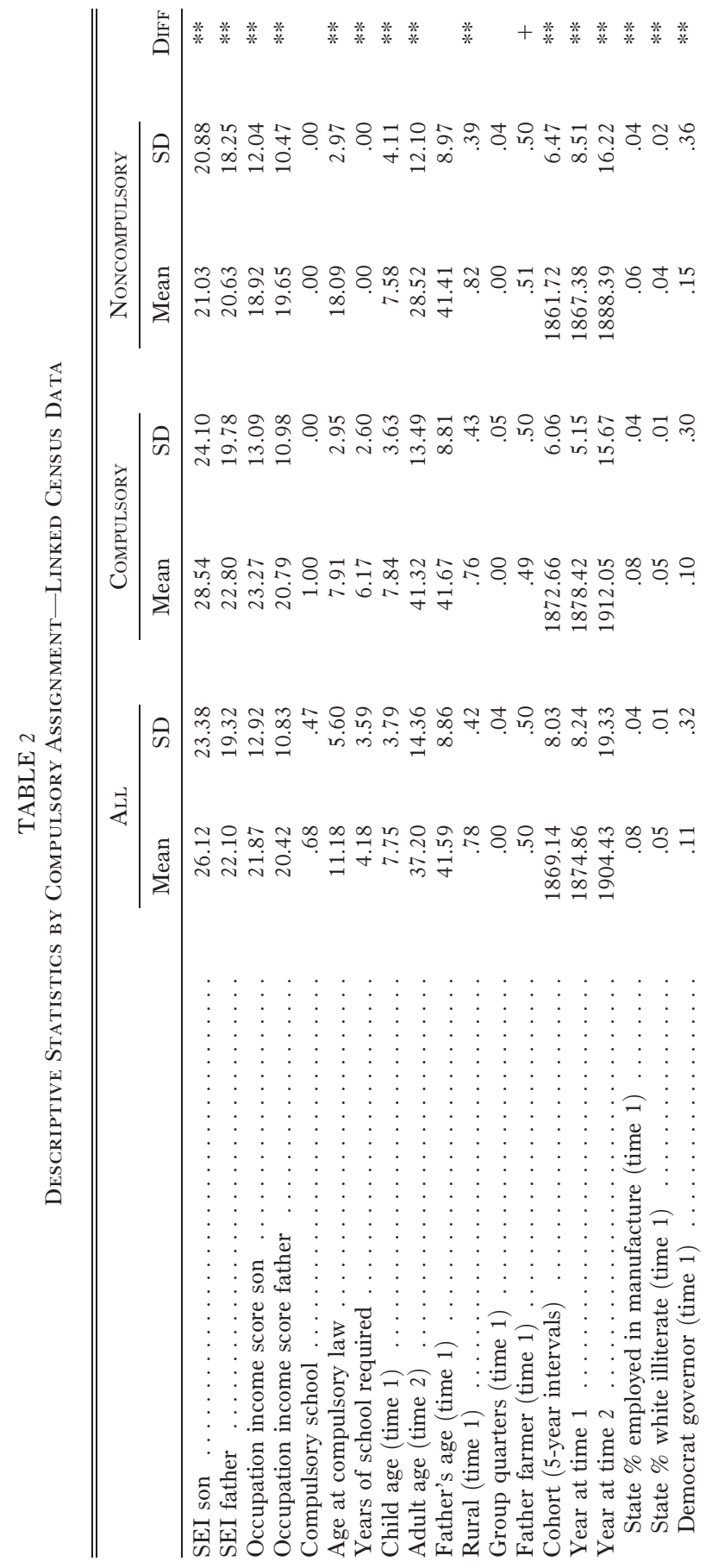

1714

This content downloaded from 129.237.045.152 on May 04, 2017 09:59:46 AM 


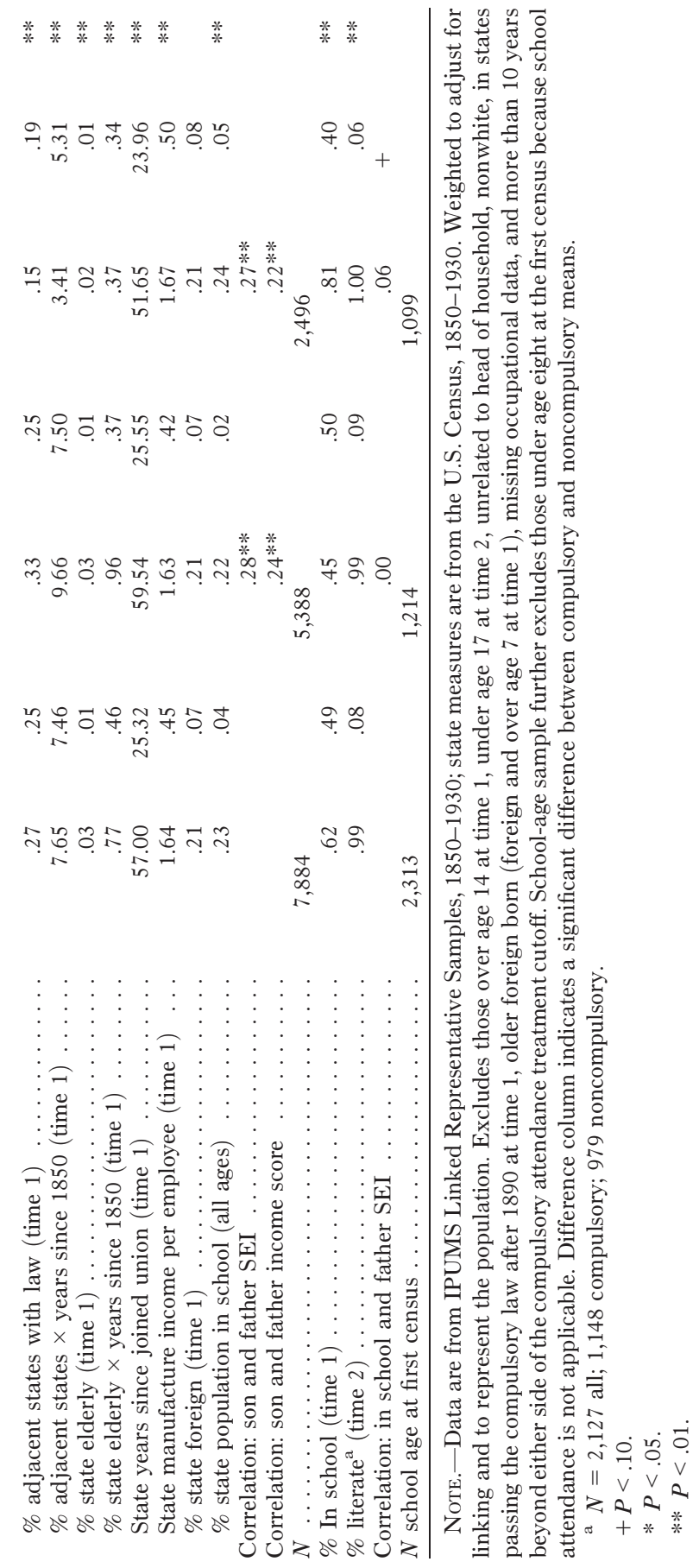

1715

This content downloaded from 129.237.045.152 on May 04, 2017 09:59:46 AM All use subject to University of Chicago Press Terms and Conditions (http://www.journals.uchicago.edu/t-and-c). 


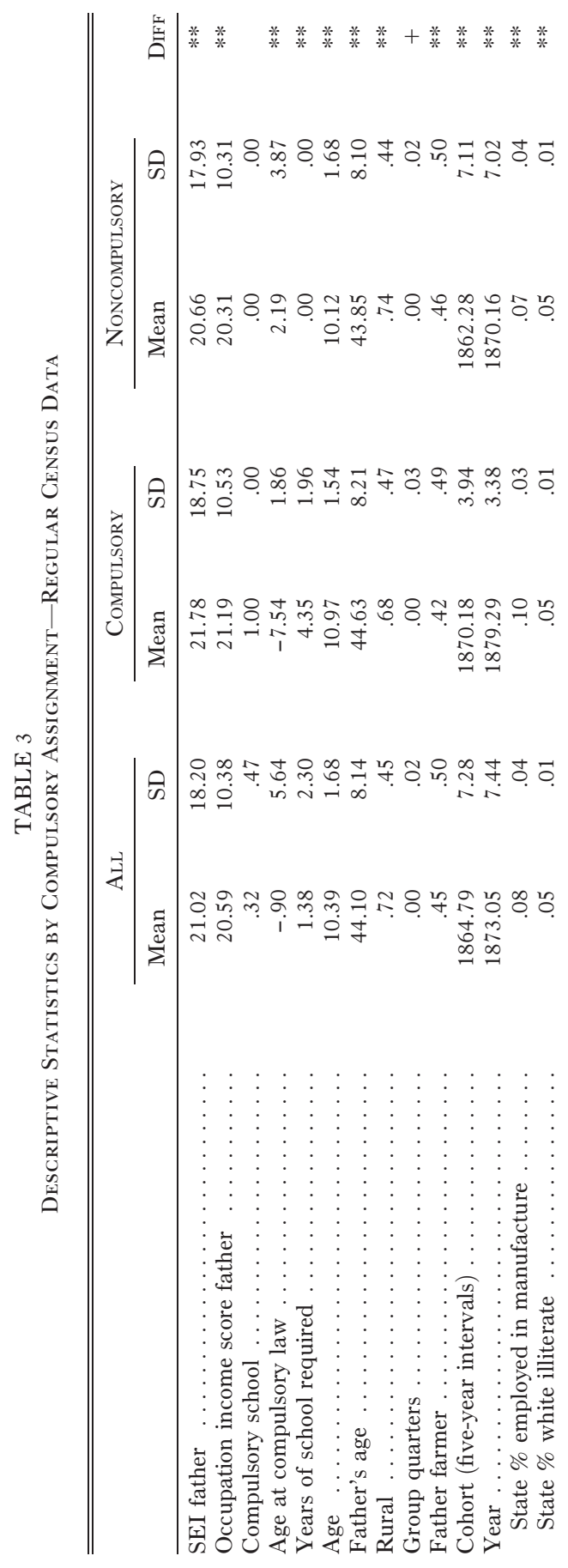

1716

This content downloaded from 129.237.045.152 on May 04, 2017 09:59:46 AM 


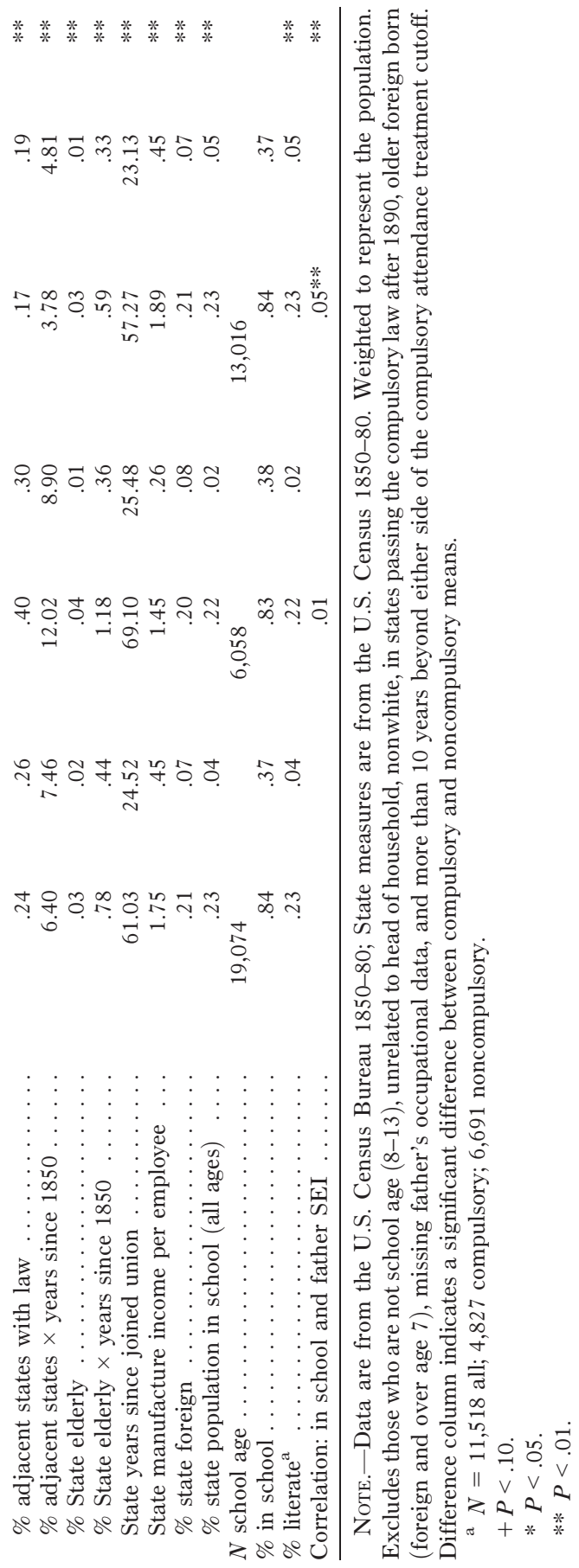

1717 
in the regular census data (table 3), the correlation between father's SEI and school attendance is significantly higher (0.05) among those not required to attend school than among those required to attend (0.01). This difference is consistent with the idea that compulsory laws increased class equality in school attendance.

\section{METHODOLOGICAL APPROACH}

Analysis proceeds in four steps. First, proportional hazard models investigate state characteristics related to the timing of early compulsory laws. All later analyses control for time-varying measures of the factors that best predict the timing of the laws among states outside the South to help rule out the possibility that some state characteristic is driving both an early compulsory law and any change in mobility. Tables 2 and 3 include these state measures and show that there are significant differences between the compulsory and noncompulsory means of these measures. ${ }^{18}$

Second, regressions investigate the effects of compulsory laws on school attendance by father's occupation. The hypothesized effects of the laws on mobility are based on the assumption that they made school attendance more equal by class. This second step asks whether this is true and sets the stage for step $3 .{ }^{19}$ Third, the main analysis uses a variety of techniques to investigate the effect of compulsory laws on intergenerational mobility. The fourth step investigates potential explanations for the results found in step 3 using state-level data on school spending, teacher-to-student ratios, and youth employment.

\section{Preliminary Analysis: Effects of the Compulsory Laws on Attendance}

Compulsory laws are exogenous at the individual level. Individuals cannot self-select into being required to attend school. Aside from random differences, age at the time of the law (which can be controlled) should be the only difference between those required to attend and those not required to attend.

Regression discontinuity (RD) exploits a cutoff, such as that created by compulsory attendance laws, as leverage to approach a causal estimate. By examining the difference between a treatment and control group within a narrow window around an assigned cutoff point, regression discontinuity

\footnotetext{
${ }^{18}$ Details about this preliminary analysis are not included here but are available upon request. Controls include manufacturing employment rate, white illiteracy rate, Democrat governor, proportion of adjacent states with the law, proportion elderly, proportion foreign born, manufacturing production per employee, years since union membership, and proportions of elderly and adjacent states with the law multiplied by years since 1850 to allow their effects to vary over time.

${ }^{19}$ The most relevant analyses and results of this step are included here. More details are available in Rauscher (2014).
} 
provides a causal estimate of the treatment effect among otherwise similar individuals (Imbens and Lemieux 2008; Lee and Card 2008; Lee and Lemieux 2010). Key assumptions include the following: meaningful unobserved differences between those within a narrow window on either side of the cutoff are eliminated; and other factors related to the outcome vary continuously over the assignment variable, which is controlled in the regression (Lee and Lemieux 2010, p. 287). Limiting analysis to a narrow window on both sides of the treatment cutoff leaves individuals who should be similar, except for observed (and controlled) differences in the forcing variable that assigns individuals to the treatment group.

To check the validity of the RD approach, I look for discontinuities in the forcing variable and in a variety of measures by the forcing variable. Discontinuities in the density of the forcing variable could suggest that individuals manipulated themselves around the cutoff (McCrary 2008). In this case, individuals could have lied about their age to avoid being required to attend school and compulsory assignment would no longer be exogenous. Discontinuities in other variables that should be unrelated to the forcing variable could suggest that the RD assumptions do not hold. I do not find evidence of sharp discontinuities in the forcing or other variables, which supports the validity of the RD approach here. The appendix includes graphs of the forcing variable and a few key covariates (father's SEI, father's age, and manufacturing production per employee; others are available upon request).

Figure 2 illustrates the RD approach. In this analysis, the sample is limited to a small window 10 years on either side of the compulsory assignment cutoff. ${ }^{20} \mathrm{RD}$ requires controlling for the forcing variable (in this case age at the time of law, called CompCohort in eq. [1]), which determines whether an individual was ever required to attend school. Equation (1) also interacts the assignment variable with the treatment- $\beta_{5}$ - to allow the relationship to vary between treatment (called CompSchool) and control groups. Models only include states with statistical support (i.e., states passing the law in or before 1890), meaning they have individuals in both the treatment and control groups.

$$
\begin{aligned}
\text { InSchool }_{i j k m}= & \alpha+\beta_{1} \operatorname{DadOcc}_{i j k m}+\beta_{2} \operatorname{CompSchool}_{i j k m} \\
& +\beta_{3} \operatorname{DadOcc}_{i j k m} \times \operatorname{CompSchool}_{i j k m}+\beta_{4} \operatorname{CompCohort}_{i j k m} \\
& +\beta_{5} \operatorname{CompCohort}_{i j k m} \times \operatorname{CompSchool}_{i j k m}+\beta_{6} X_{i j k m} \\
& +\operatorname{Cohort}(5 \mathrm{yrs})_{j}+\operatorname{CensYr}_{k}+\operatorname{State}_{m}+\varepsilon_{i j k m} .
\end{aligned}
$$

\footnotetext{
${ }^{20}$ The width of the window involves a trade-off between internal validity and sample size. Sensitivity checks using a five-year window are conducted for analyses based on the indicator of whether an individual was ever required to attend school and yield similar results. Investigation of the nonlinear pattern requires a 10-year window.
} 


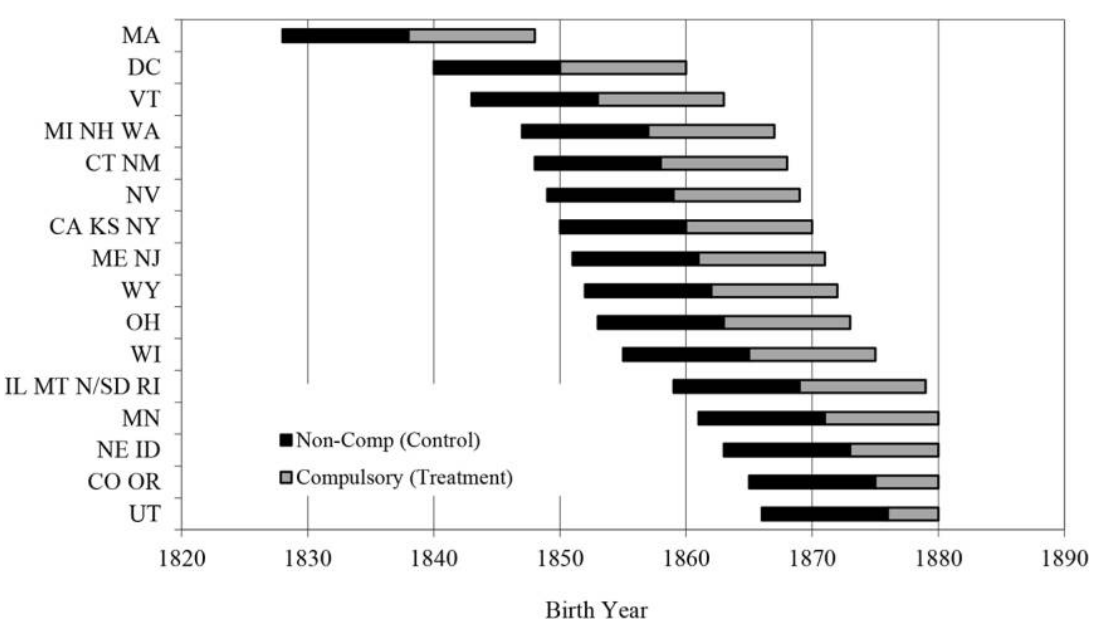

FIG. 2.- Regression discontinuity design-10-year "treatment" and control window

With state, year, and cohort fixed effects and continuous age measures, $\beta_{1}$ represents the association between father's occupation score and likelihood of attending school (class inequality in school attendance) for individuals not required to attend school, $\beta_{2}$ is the relationship between compulsory assignment and school attendance among those with mean father's occupation score, and $\beta_{3}+\beta_{1}$ is the association between father's occupation and school attendance for those required to attend school. The parameter of interest- $\beta_{3}$-indicates the relationship between compulsory assignment and class inequality in school attendance. If the compulsory law reduced class inequality in school attendance, $\beta_{3}$ should be negative. Cohort (in five-year intervals), census year, and state fixed effects control for changes over time and state differences. ${ }^{21}$ Controls (represented by $X$ ) include son's age (in both censuses in the linked census data) and father's age in the first census (and squared terms for each) as well as rural residence, group quarters residence, state measures related to the timing of compulsory laws, and an interaction of compulsory assignment with every control variable in the model. In addition, all models control for the proportion of the total state population of any age in school. This allows more precise estimates of compulsory effects on attendance among school-age

${ }^{21}$ Potentially important changes over time include economic depressions (the Panic of 1873 and depressions in 1882-85 and 1893-96) and wars (the Civil War and World War I). Year fixed effects adjust for any differences associated with a particular year, including depression or war. In the long term, compulsory attendance could reduce the likelihood of depression if it promotes economic growth. However, I limit analysis to a narrow win- 
youth targeted by the law and rules out the possibility that overall rising school enrollment rates drove changes in school-age attendance or mobility. I use a linear probability model for ease of interpretation and comparability with the main analysis, but sensitivity analyses using logistic regression yield consistent results.

\section{Main Analysis: Effects of the Compulsory Laws on Mobility}

While state-level factors were related to the timing of the law, the precise year it passed is random at the individual level. An individual who just happened to be school age when the law passed was required to attend while his counterpart - just a year or two older-was exempt. Aside from age differences and whether or not they were required to attend school, individuals within a narrow window on either side of the compulsory age cutoff are assumed to be similar. I first show father-son SEI correlations, which do not allow controls for age or other differences.

$\mathrm{RD}$ models allow a more sophisticated analysis, including a variety of state- and individual-level controls to identify the effect of compulsory laws on intergenerational mobility. The RD model is the same as equation (1), including all controls, but predicts son's occupational attainment instead of school attendance. In this model, $\beta_{3}$ estimates whether intergenerational association differed by compulsory assignment among those within 10 years of the law.

\section{Nonlinear Analysis}

Complicating the above analysis, structural lag theory hypothesizes a nonlinear relationship between educational expansion and mobility. To investigate this possibility, I first graph intergenerational SEI correlation by years of school required. Second, son's occupational attainment is regressed on years of school required (called YrsReq in eq. [2]) and its square, both interacted with father's occupation score. Rather than using the sharp cutoff of the RD approach above, equation (2) allows each additional year of schooling to matter. In equation (2), $\beta_{4}$ estimates the linear relationship between years of school required and intergenerational association and $\beta_{5}$ the nonlinear relationship. Equation (2) includes the same controls as the

dow around the compulsory law, and depressions occur at the national or industryspecific level, not just the state level. Further, depressions occurred during many years covered in this analysis, and excluding individuals in the 1930 census (which measures adult occupation during the Great Depression) — or any other census year-yields similar results. 
models above, including state, cohort, and census year fixed effects. Again, the sample is limited to those 10 years on each side of the cutoff.

$$
\begin{aligned}
\text { Occ }_{i j k m}= & \alpha+\beta_{1} \operatorname{DadOcc}_{i j k m}+\beta_{2} \operatorname{YrsReq}_{i j k m}+\beta_{3} \operatorname{YrsReq}_{i j k m}{ }^{2} \\
& +\beta_{4} \operatorname{YrsReq}_{i j k m} \times \operatorname{DadOcc}_{i j k m}+\beta_{5} \operatorname{YrsReq}_{i j k m}{ }^{2} \times \operatorname{DadOcc}_{i j k m} \\
& +\beta_{6} X_{i j k m}+\operatorname{Cohort}(5 \mathrm{yrs})_{j}+\operatorname{Cens} \operatorname{Yr}_{k}+\operatorname{State}_{m}+\varepsilon_{i j k m} .
\end{aligned}
$$

The above methods use continuous occupation measures. The appendix discusses methods based on occupational categories, sibling pairs, and state-level measures; results are consistent with those presented below.

\section{Methodological Overview}

I investigate effects of the law on equality of school attendance. Based on those results, I use an intent-to-treat estimate of a large-scale policy change to investigate the education-mobility relationship. While other studies generally compare treated and untreated individuals, an intent-to-treat estimate compares individuals who were assigned to the treatment (in this case, children required to attend school) to those who were not assigned to the treatment (not required to attend school), regardless of compliance (whether or not they actually attended). By including all targeted youth, the intent-to-treat estimate remains unbiased to heterogeneous responses to treatment assignment or noncompliance (Freedman 2006). For example, individuals who would not attend school regardless of being required may have other disadvantages — such as poverty or disability — that would also dampen their occupational attainment. Those who attend regardless of compulsory assignment may similarly attain higher occupational status. Finally, being required to attend may perversely encourage some students, who would have attended otherwise, to work instead if the law increased demand for child laborers. These defiers would bias an instrumental variable (or treatment-on-the-treated) estimate. An intent-to-treat estimate is robust to these responses and also allows compulsory laws to influence mobility through mechanisms other than school attendance (Freedman 2006). Overall, this approach provides a rare opportunity to address some endogeneity in the apparent link between education and mobility during a large-scale change. ${ }^{22}$ It helps to understand what happens when a policy changes rather than just how a treatment affects a few individuals.

\footnotetext{
${ }^{22}$ One limitation of examining a large-scale policy change is potential violation of the stable unit treatment value assumption (SUTVA). That is, causal inference relies on the assumption that cases are independent or that the treatment of one individual does not influence that of another. In this case, individuals required to go to school could have encouraged attendance among those not required to attend. Alternatively, those in the
} 
Like previous research, this study uses state compulsory attendance laws to account for individual selection into education. However, to build on existing research, this project (1) examines effects on intergenerational occupational mobility rather than occupational attainment or earnings; (2) uses the first compulsory enrollment law in each state, which may affect a larger group of youth than the later changes to these laws used in other research; (3) uses an intent-to-treat estimate; and (4) controls for factors related to the timing of state compulsory education laws, with the hope of addressing any important state differences.

\section{RESULTS}

\section{Effects on Attendance}

Results suggest that the compulsory laws increased equality of school attendance. At the state level, figure 3 shows a sharp increase in average state attendance rates for white, low-SEI boys between the censuses on either side of the compulsory law. However, higher-SEI youth do not show the same pattern; there is no change in high-SEI attendance rates between the censuses immediately before and after the law. The class gap in boys' school attendance narrows with the compulsory school laws.

Regression results support the equalizing effect of the compulsory laws on attendance. ${ }^{23}$ As table 4 shows, father's occupation was significantly less related to school attendance under the compulsory law. The equalizing effect of compulsory schooling holds with or without controls for state and individual residential differences (models 1 and 3). Thus, comparing otherwise similar young men, compulsory assignment significantly increased equality of school attendance. ${ }^{24}$ As models 2 and 4 show, this effect does not follow a nonlinear pattern. The relationship between father's SEI and attendance decreases with each additional year of required schooling but does not differ by its square.

noncompulsory group could have learned from those in the compulsory group without ever attending school. Both of these potential spillover effects should generate social returns to compulsory schooling and, by providing more equal access to school-related skills, lead me to underestimate individual returns. Therefore, this potential underestimation increases the likelihood of finding support for conflict theory over status attainment and structural lag arguments.

${ }^{23}$ State-level regression results are shown in the appendix.

${ }^{24}$ Although educational attainment is not included in any census until 1940, supplementary analyses based on the 1940 census find that early compulsory laws significantly reduced the educational attainment gap between white and nonwhite men (Rauscher 2014). Father's class is not available among the cohorts affected by early compulsory laws in the 1940 census because they are elderly, but using race as a proxy for class background suggests that compulsory laws significantly increased equality in educational attainment as well as attendance. 
American Journal of Sociology

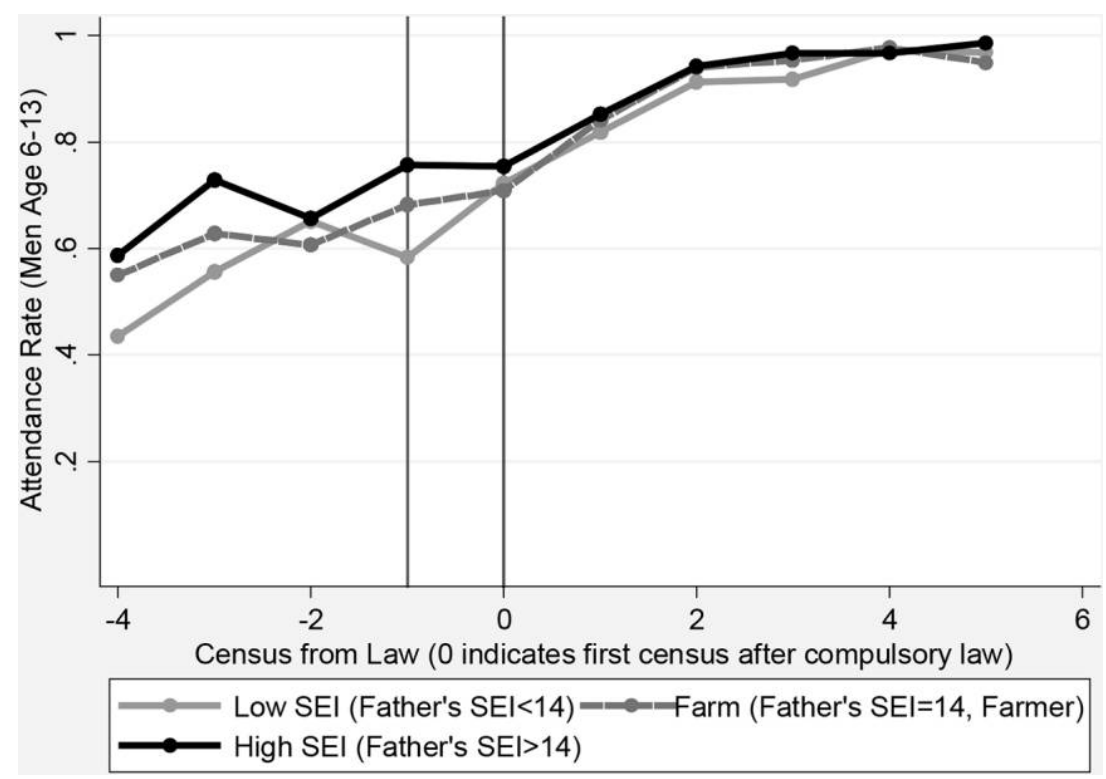

FIG. 3.-Average state attendance of school-age white males by census from compulsory law. Sample excludes states passing the law after 1890. Data are from IPUMS Individual Census Data, 1850-1920. Horizontal lines indicate the census years immediately before and after the compulsory law in each state. Compulsory laws are related to educational expansion; the first census after the law shows greater equality in attendance by father's occupational status and a greater increase in attendance for youth from lower-status backgrounds (father's SEI < 14).

\section{Effects on Mobility}

As the bottom of table 2 shows, within 10 years of the passage of the compulsory law intergenerational correlations are slightly higher among those required to attend school, but the differences are not significant. Similarly, figure 4 illustrates that the father-son SEI correlation is slightly higher among sons required to attend school for one to five years than those never required to attend.

However, examining the group required to attend for six to nine years provides evidence of a nonlinear relationship. In other words, the correlation results suggest that immediately after the law intergenerational association increased for the first five years and then declined again during the next five years. Mobility decreased and then increased, not quite returning to prelaw levels. The differences in these correlations, however, are not significant.

Results from the full RD model in table 5 echo the correlations. With all controls included, the interaction effect between compulsory school and 
father's SEI is positive and significant $(\beta=0.04 ; P<.05) .{ }^{25}$ Expanding school attendance by class background appears to have increased intergenerational association. Intergenerational mobility is therefore lower for sons required to attend school. ${ }^{26}$ When limiting the sample to adults ages 30-64, however, the $\mathrm{RD}$ models in table 6 suggest that there is no linear effect of compulsory school assignment on intergenerational association.

\section{Nonlinear Mobility Pattern}

Complicating the story to allow a nonlinear effect offers a more complete picture. Years of required schooling has a nonlinear relationship with mobility. With or without controls, models 2 and 4 in table 5 find that the interactions between father's SEI and both years of school required and its square are significant. Figure 5 illustrates the nonlinear pattern. Sons required to attend four years of school experienced the strongest association with father's SEI-accruing the greatest boost for higher paternal SEI scores. In contrast, those required to attend the maximum of nine years saw the lowest return to father's SEI (nearly the same as those never required to attend) and the most mobility. This nonlinear pattern holds when limiting the sample to adults ages 30-64 (table 6).

To summarize, compulsory laws made school attendance more equal by social background. However, contrary to common assumptions and status attainment arguments, this greater equality in access to education appears to have been accompanied by lower intergenerational mobility (or at least unchanged mobility among older adults ages 30-64). A more complicated picture emerges when allowing effects to vary by years of school required; this strategy reveals a nonlinear relationship between years of school required and intergenerational association. In other words, the earliest cohorts - those required to attend only a few years - experienced lower mobility, while mobility returned to prelaw levels among those required to attend closer to nine years. This nonlinear pattern remains when limiting

\footnotetext{
${ }^{25}$ Regressions use standardized SEI measures, so coefficients do not need to be adjusted for changes in the distribution between generations.

${ }^{26}$ In model 3, table 5, the coefficient for father's SEI score is 0.19 among noncompulsory sons and 0.23 among sons required to attend school. This is lower than the 0.4-0.6 estimate consistently found in studies of earnings elasticity using more recent data (Mazumder 2005; Jantti et al. 2006), which may reflect measurement (standardized SEI as opposed to log earnings) or model differences. For example, in model 1 with fewer controls, the coefficient of father's SEI score is 0.23 and 0.27 for noncompulsory and compulsory individuals. The difference could also indicate higher mobility in the late $1800 \mathrm{~s}$ (Ferrie 2005). A recent analysis suggests that higher estimates of late-1800s mobility reflect an overrepresentation of sons of farmers, all of whom cannot remain on the farm (Xie and Killewald 2010). However, results from this study are similar when excluding sons of farmers or including an indicator for that group (with or without a "farm $\times$ years required" interaction).
} 


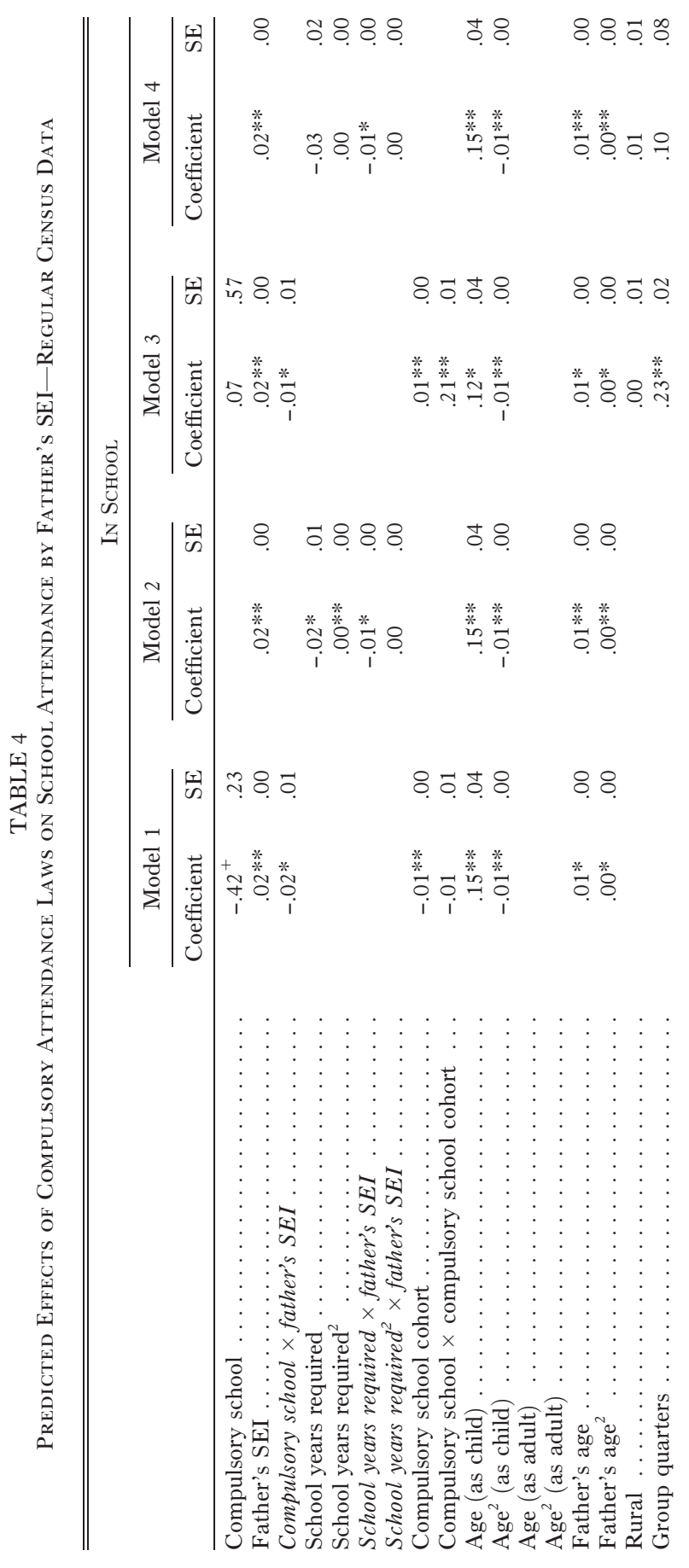

1726

This content downloaded from 129.237.045.152 on May 04, 2017 09:59:46 AM 


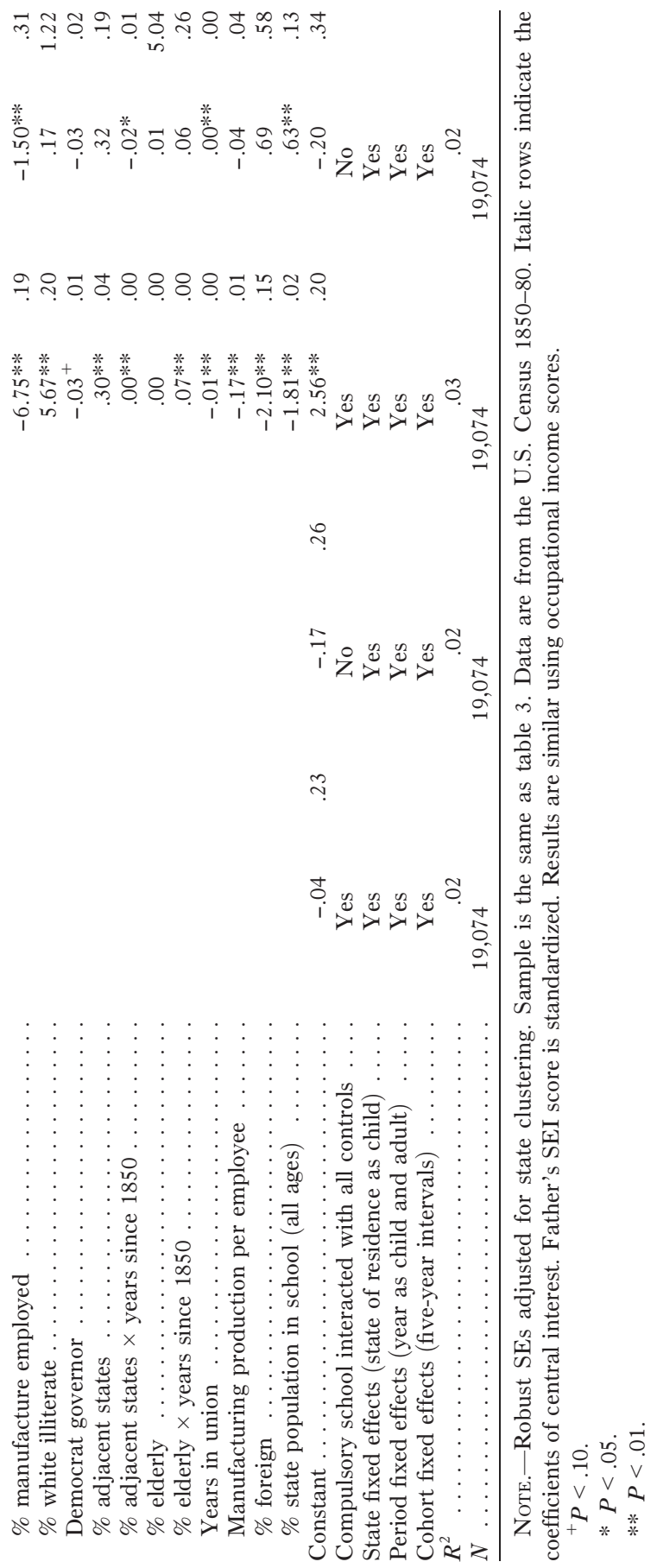

1727

This content downloaded from 129.237.045.152 on May 04, 2017 09:59:46 AM 
American Journal of Sociology

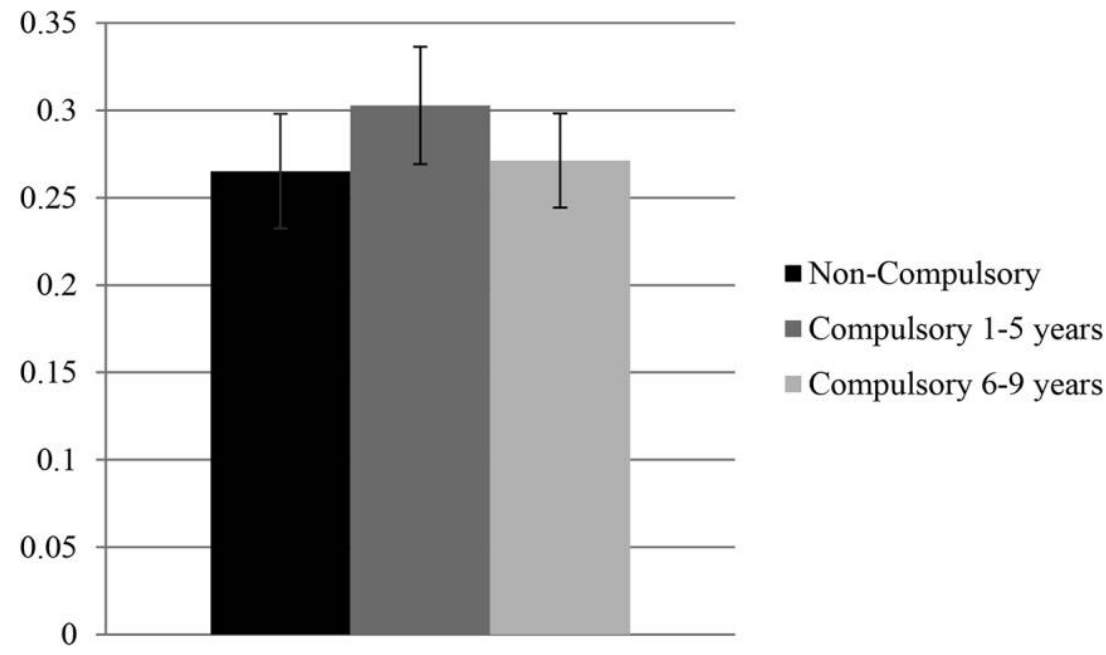

FIG. 4.-Correlation of father-son SEI scores by required school attendance. Noncompulsory sample includes sons 10 years beyond the compulsory attendance treatment cutoff. The sample is weighted to represent the population. Data are from IPUMS Linked Representative Samples, 1850-1930.

the sample to adults ages 30-64, with a narrower difference in age at occupation between the compulsory and noncompulsory groups (table 6). The nonlinear pattern also holds in a variety of sensitivity checks, including use of occupational income scores, a categorical measure of class, and sibling pair analyses (see the appendix). ${ }^{27}$

\section{Understanding the Nonlinear Relationship}

The nonlinear pattern is surprising but consistent with the idea that the school system was unprepared for the policy change and slow to respond. While I cannot definitively explain the nonlinear mobility pattern here, this section investigates potential contributing factors. Evidence is most consistent with a structural lag explanation, but other possible explanations cannot be ruled out.

As suggested by the structural lag argument, school quality may initially have become less equal after the compulsory laws. For example, because the laws had the greatest effect on low-SEI attendance, it is plausible that schools in lower-class areas became more crowded and enrolled older and

${ }^{27}$ To address potential concerns that results reflect changes in the occupational distribution, I add controls for state occupational score distributions, including state SEI mean, standard deviation, coefficient of variation, or changes in these state measures between individual observation years. Results remain unchanged. 
more difficult or disruptive types of students, who would otherwise have been "street urchins" or truants. Very little historical research has investigated school or neighborhood segregation in the late 1800s. In perhaps the most relevant study, Zunz (1982) examines ethnic and class segregation in Detroit from 1880 to 1920 . He finds a very high degree of segregation, particularly by ethnicity but increasingly by class, coupled with strong class inequality by ethnicity. Importantly, Zunz (1982) notes the tight connection to neighborhood institutions, such as churches and schools. This is consistent with the structural lag explanation because, given strong segregation and ties to neighborhood schools, children would likely attend school in their own neighborhood with others from similar social backgrounds. Because the compulsory laws targeted, and primarily affected, lower-class children, the effect of the laws would be unequally distributed across schools within the same city. Schools primarily attended by higher-class children would not have experienced the same crowding and disruption as those in lower-class areas. Thus, through structural lag, compulsory laws may initially have reduced mobility by unintentionally making the quality of schooling less equal. In statistical terms, the compulsory laws may have reduced the quality of schooling among "always-takers" from lower- but not higher-class backgrounds.

Public school funding is consistent with the structural lag explanation. Figure $6 a$ shows mean state public school spending per capita by census from the compulsory law. Average school spending increased at a constant rate until the first census before the law. The first census after the law shows a continuation of previous public school spending levels. However, by the second census after the compulsory law, school funding had increased sharply and continued to rise drastically several censuses after the law. In other words, school funding did not anticipate the increased burden that compulsory laws would place on schools.

School funding could help mobility recover by increasing the teacher-tostudent ratio. Figure $6 b$ shows that the average state teacher-to-student ratio remained flat through the first census after the compulsory law. By the second census after the law, however, the ratio of teachers to students had increased sharply. Funding also enabled new and more attractive schools (e.g., five years after the New York compulsory attendance law, New York City built four new schools and expanded several others) as well as the conversion of common into graded schools; both of these changes attracted more students and encouraged more consistent attendance (Cutler 1989; Lassonde 1996). Graded schools separated students into grade levels based on age and academic progress, thus providing a structural response to the increasing diversity of students. Rather than trying to teach students of all levels in one room, graded schools allowed greater efficiency by targeting students at a similar level, but at the same time increased inequality within 


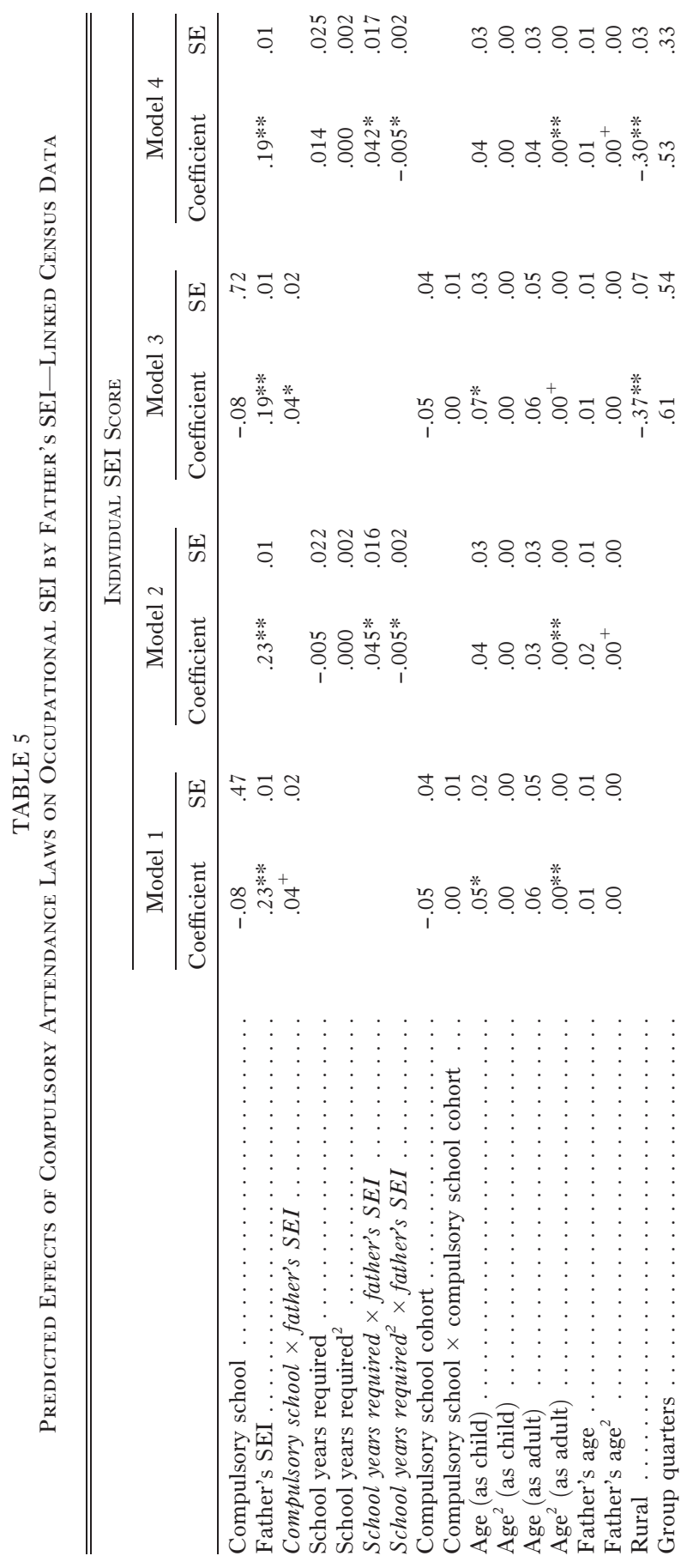

1730 


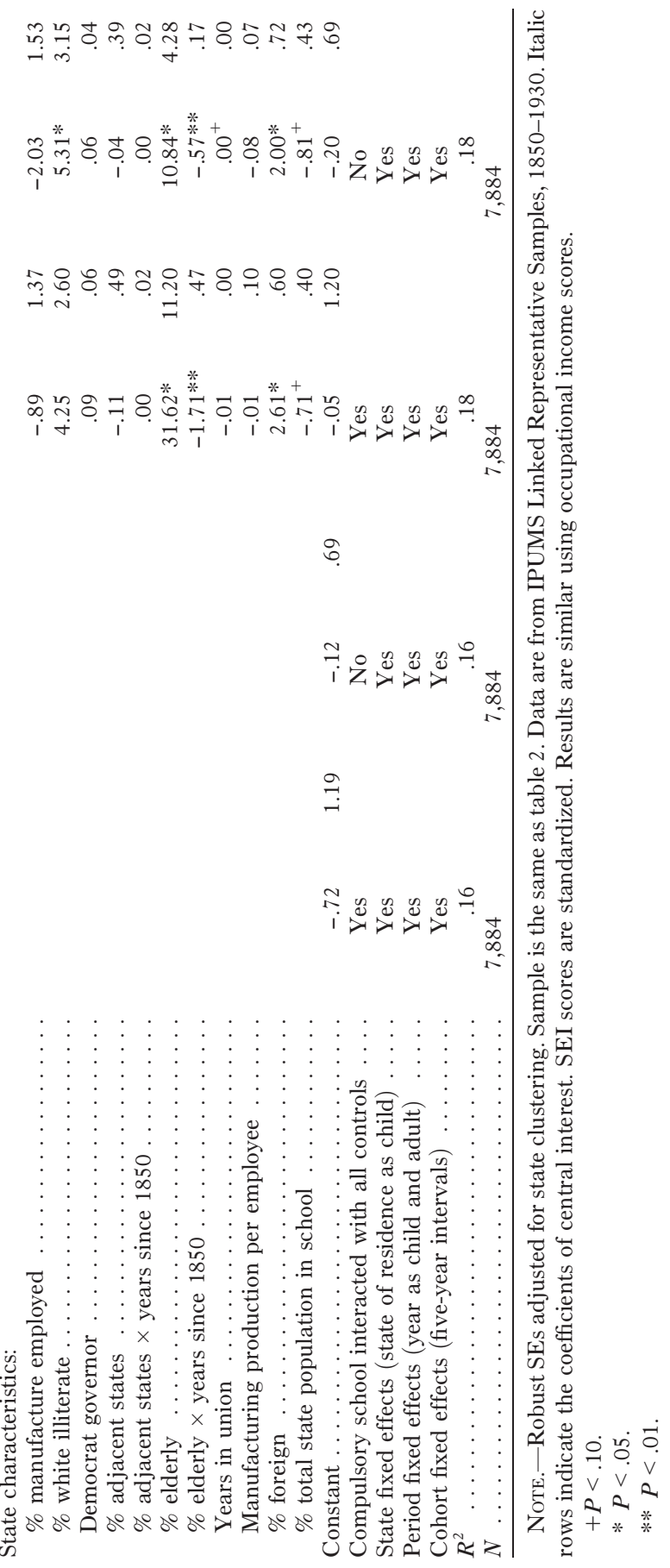

1731

This content downloaded from 129.237.045.152 on May 04, 2017 09:59:46 AM 


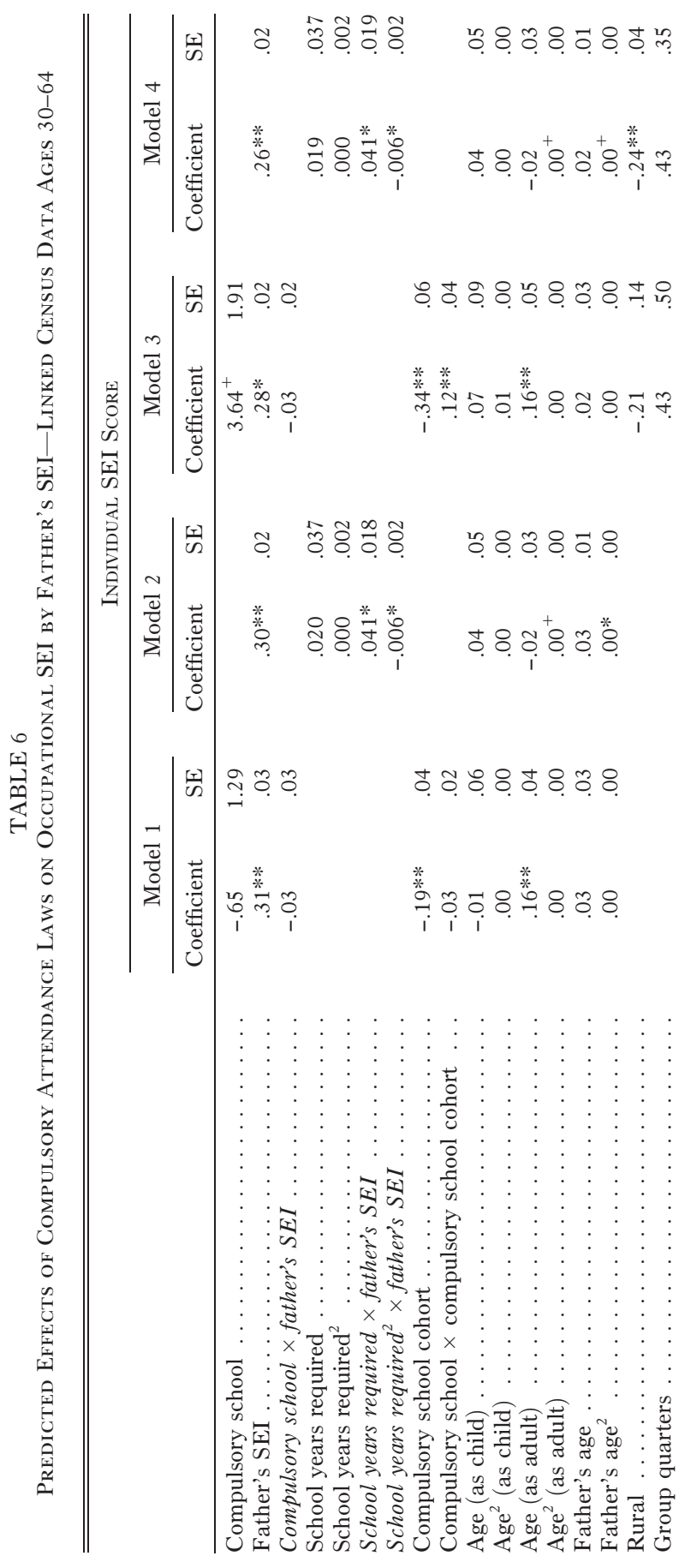

1732 


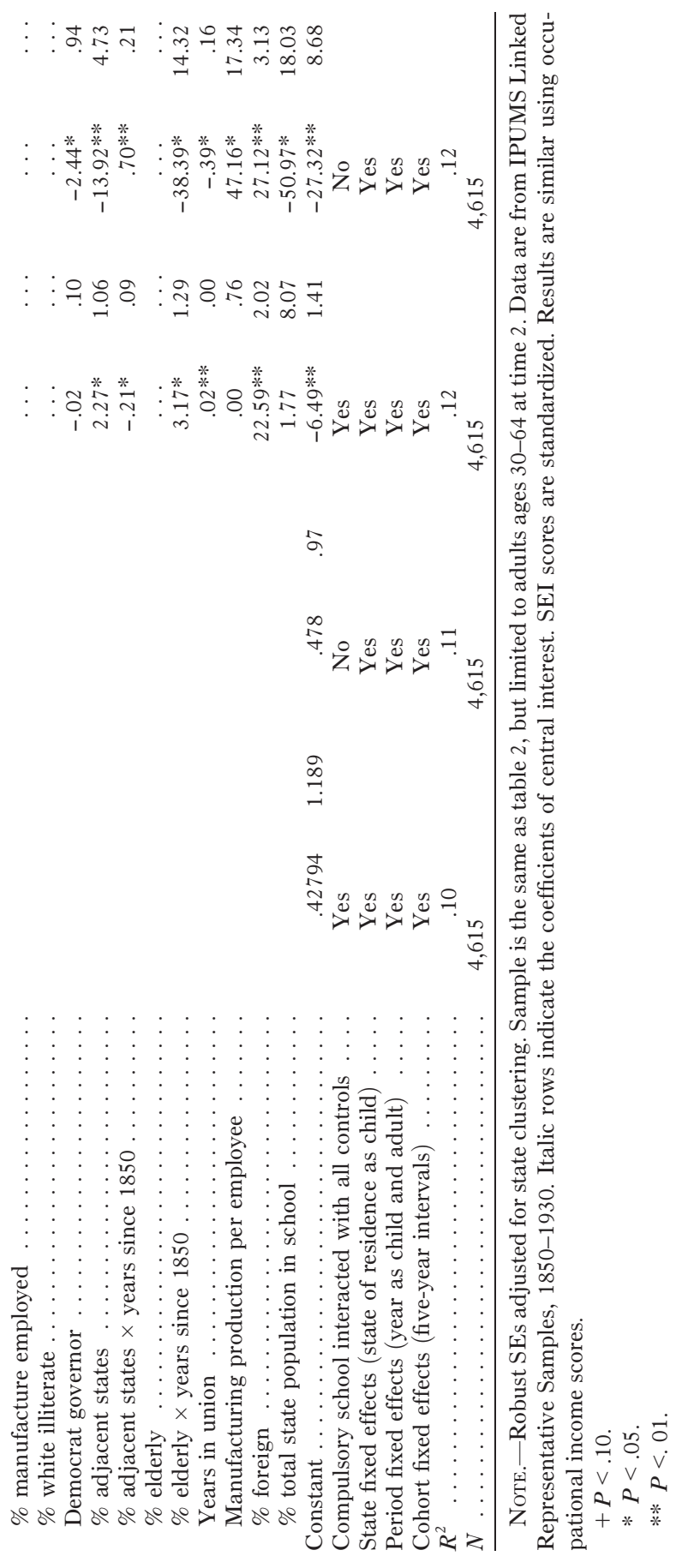

1733

This content downloaded from 129.237.045.152 on May 04, 2017 09:59:46 AM All use subject to University of Chicago Press Terms and Conditions (http://www.journals.uchicago.edu/t-and-c). 
American Journal of Sociology

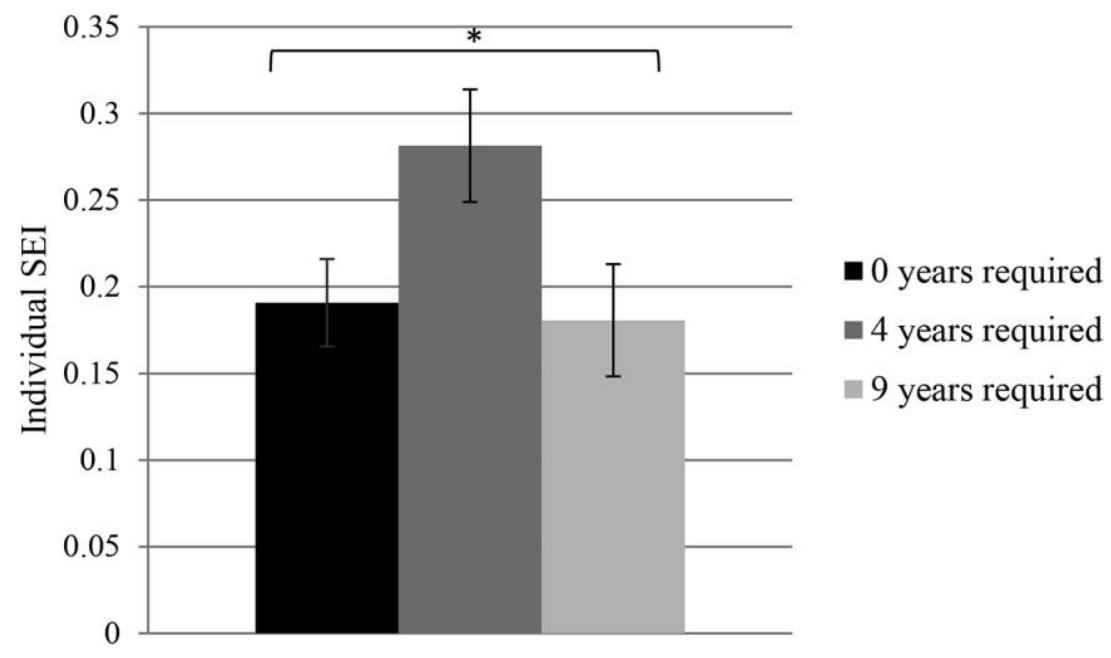

FIG. 5.-Predicted intergenerational association by years of compulsory attendance. This figure shows son's SEI increase (in standard deviation units) for each standard deviation increase in father's SEI score by years of school required. Sample is limited to sons 10 years on either side of the compulsory attendance treatment cutoff and weighted to represent the population. Estimates based on model 4 in table 5. Data are from IPUMS Linked Representative Samples, 1850-1930.

and between schools (students faced unequal chances of failing a grade or dropping out based on social background and city; Ayres 1909).

Finally, as suggested by Lassonde (1996) for late 19th-century New Haven, compulsory schooling may initially have been ineffectively enforced in all towns. Lax enforcement, however, does not seem able to explain the nonlinear mobility pattern because a nonlinear relationship is not found for equality of school attendance. In addition, even lax enforcement should encourage — not initially discourage — attendance.

To summarize, states maintained initial levels of school funding and teacher-student ratios after the laws. After a short lag, however, both measures increased sharply. Thus, despite higher attendance rates and new types of students who were more difficult to teach, there was little institutional response at first. After this initial lag, the data suggest that school systems adjusted to the policy change, increased funding, and increased the teacher-student ratio.

An alternative explanation for the nonlinear pattern involves the relationship between school attendance and youth employment. Boys who were required to attend for only a few years may have sacrificed work opportunities that could have facilitated mobility without spending enough time in school to gain skills relevant for the job market. However, examining child employment rates reveals a continuous linear decline through the 

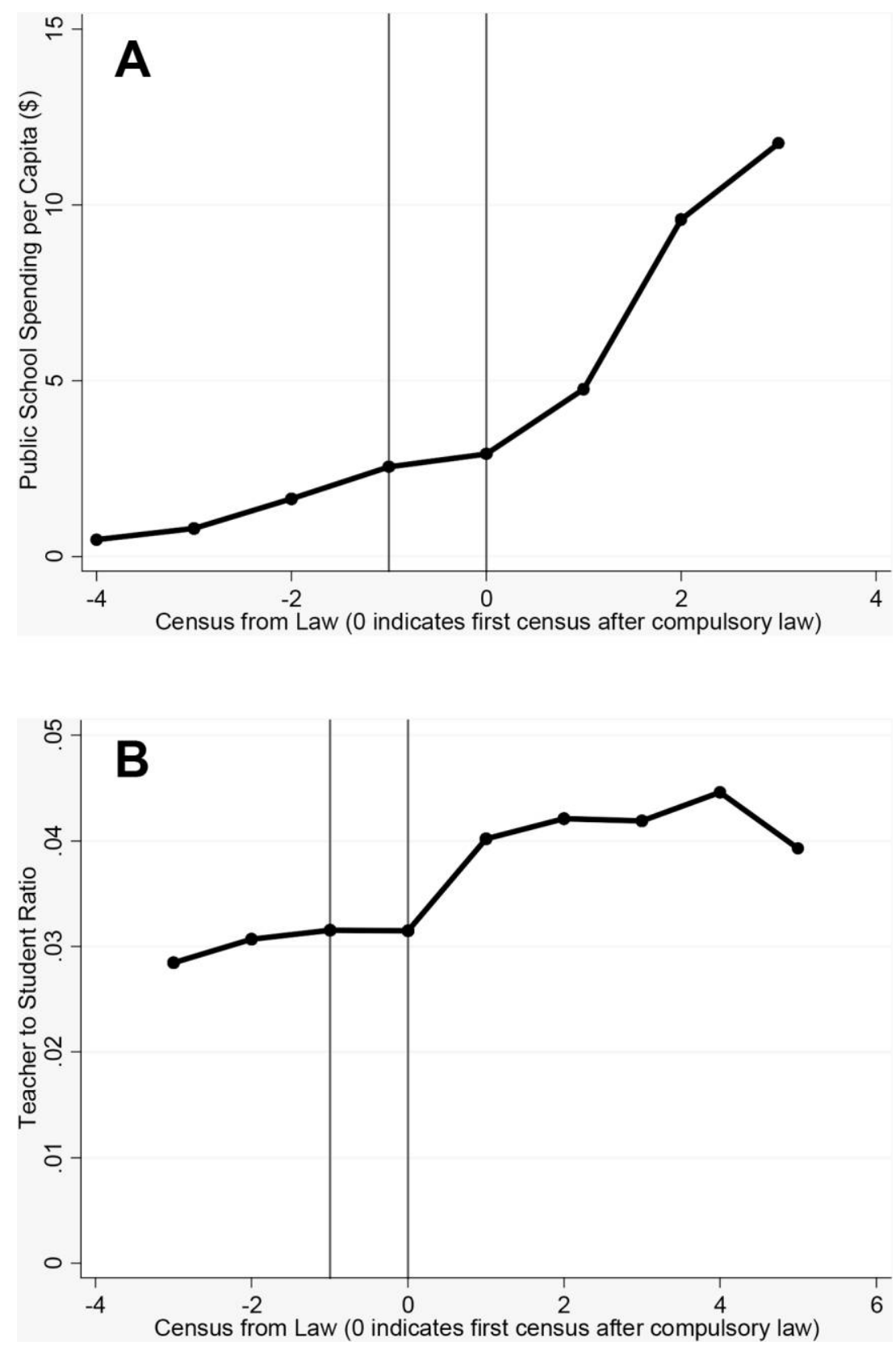

Fig. 6.- $A$, Mean state public school spending per capita 1850-1920. Sample excludes states passing the law after 1890. Public school spending per capita measures total state spending on public schools per total state population each census year (excluding spending on colleges, academies, postsecondary, and normal schools). Years 1850-1870 are based on total school income for all schools. $B$, Mean state teacher-to-student ratio 18501920. Sample excludes states passing the law after 1890. Teacher-to-student ratio measures the ratio of people employed as teachers to total students in a state. Data are from ICPSR (1970) and U.S. Bureau of the Census (1975). 
compulsory law. Figure 7 graphs mean state employment rate among schoolage white boys. There is no change in the rate of decline with the law, which suggests that the law did not affect employment. This makes sense because the laws generally had flexible attendance requirements (e.g., 12 weeks with six of them consecutive). Some areas even had evening school. These flexible arrangements would allow a child to work while attending school. Note, however, that youth employment data are only available from 1880, so unlike the rest of the analyses in this article, figure 7 includes all states rather than only states with early compulsory laws. In addition, steadily declining employment rates could mask sharp decreases in hours worked, translating into less work experience or job skill development. The school flexibility noted above would help maintain work hours and skill development, but employment rates alone cannot rule out this youth employment explanation for the nonlinear pattern.

Another possibility is that labor demands created by many youth leaving the workforce to attend school may have increased child wages for a short period after the law, which unequally discouraged attendance among the poor and initially reduced mobility. However, figure 7 belies this large drop in employment and, based on limited child wage data for 1870-1900 from the Census Bureau, mean state child wages do not show a sharp increase

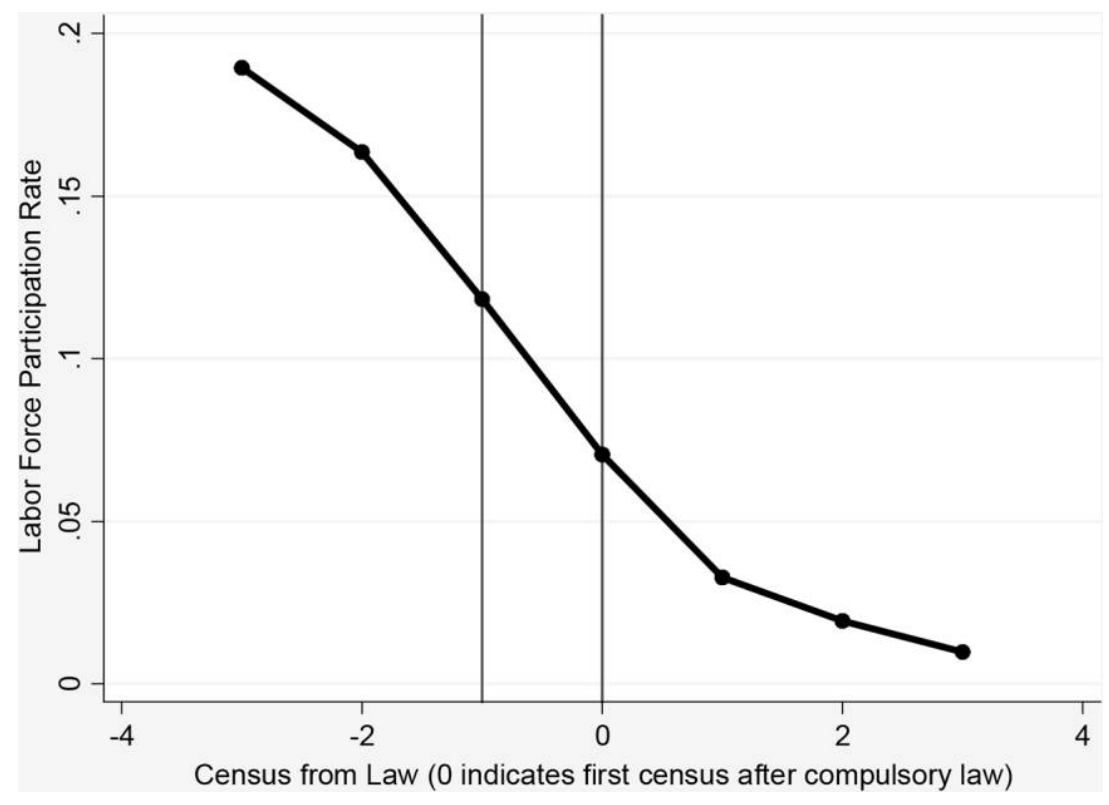

FIG. 7.-Employment rates among school-age white men. Sample includes all states because youth employment information is not available until 1880. Data are from IPUMS Individual Census Data, 1850-1930. 
after the law. If anything, the growth of child wages decreases after the law regardless of whether I use CPI adjusted, GDP deflated, or raw wages.

A third potential explanation for the nonlinear mobility pattern, consistent with conflict theory, is that upper-class parents initially panicked about the compulsory laws, possibly fearing schools would be flooded by lower-class kids who would "contaminate" their children with lower-class behaviors and culture. As a result of this anxiety, they may have moved their children to a better quality school. To explain the nonlinear pattern, however, after an initial period of panic these high-SEI parents would have had to move their children back to their previous school or allowed low-SEI children equal access to their elite schools. In other words, this "elite flight" explanation would have had to be short-lived in order to explain the nonlinear mobility pattern.

In summary, evidence supports a structural lag explanation for the nonlinear mobility pattern. ${ }^{28}$ However, because length of required attendance is confounded with time since the law, I cannot definitively identify which of these is the driving factor. Furthermore, other potential explanations for the nonlinear relationship include elite flight, youth employment, youth wages, or ineffective enforcement. While I briefly address each of these above, space limitations rule out further analysis here. Future research should further investigate these and other potential explanations.

\section{CONCLUSION}

Evidence of a relationship between compulsory laws and mobility contradicts arguments that relative mobility is not systematically related to policy or other changes (Sorokin 1959; Erikson and Goldthorpe 1992). Although compulsory laws made school attendance more equal, results of the above analyses suggest that they initially reduced intergenerational mobility. Af-

\footnotetext{
${ }^{28}$ Articles in the New York Times are also consistent with this scenario. For five years before the compulsory law in New York, there were no articles complaining about school crowding or the need for separate truant schools in the New York Times. Shortly after New York made attendance compulsory in 1874, however, a rash of these articles appeared in the New York Times. For example, in 1877, "unruly and vagrant children cannot be kept in school, and . . . when there they corrupt the good and industrious children" (New York Times 1877). A year later, another article states, "As is well known, we have not school room enough in certain wards, and we provide too much for the well off and too little for the poor" (New York Times 1878). The New York Times articles that note crowding and disruption (or the need for separate truant schools to house disruptive students) sprang up immediately after the compulsory law in 1874 and declined about five years after the law. That year, in 1879, New York City built four new schools and expanded several others to try to meet demand for school space. Thus, these historical documents from New York are consistent with the institutional lag argumentthat the school system was slow to respond to the policy change.
} 
ter this initial reduction, mobility increased again, returning to prelaw levels after about 10 years.

Studying early 20th-century Iowa, Parman (2011) finds a similar decline in (income) mobility following public school expansion. He suggests that this decrease may have dissipated over time - as lower-income families caught up to faster-responding higher-income families - but data limitations prevent him from investigating that possibility. Using data that span multiple census years and cohorts, this study finds evidence of such a nonlinear relationship between educational expansion and mobility. Applications of conflict theory typically rely on upper-class action to explain reproduction of inequality (Collins 1971). In this case, however, the compulsory laws primarily affected lower-class children, which suggests that the initial decline in mobility did not require action by upper-class families.

Rather, evidence supports a structural lag explanation. Even without elite efforts to maintain advantage, it seems that educational expansion through compulsory attendance laws inadvertently reduced mobility through institutional inertia. School funding and teacher-to-student ratio data indicate that the school system was initially unprepared for the policy change and, as a result, was slow to respond to the new educational policy landscape. Because of this institutional lag, school quality became less equal and mobility initially declined until the system caught up and mobility bounced back to prelaw levels.

This study uses historical data, which raises concerns about generalizing to today. First, the economy was going through rapid industrialization in the late 1800s, whereas today we live in a knowledge economy (Powell and Snellman 2004). Equalizing a nonuniversal level of education such as college could increase mobility today. Second, this study is about raising the minimum level of schooling to primary school attendance, not secondary or postsecondary school, which is where current equalizing efforts are focused. Students in the late 1800s were learning to read, write, and do basic arithmetic. Effects could differ at the postsecondary level. Third, the U.S. population was different in the late 1800s; a large proportion of families were first or second generation immigrants, religious and ethnic differences were fraught with tension, and inequalities were stark. Finally, the study is limited to white men. I exclude nonwhites and women because of concerns about their intergenerational data quality and to stack the odds in favor of status attainment arguments, which expect education to boost occupational opportunity most for white men (because of discrimination against women and minorities). However, including women and nonwhites could yield different results. The above points limit the weight these findings carry today.

Despite the limitations of historical data, results suggest two potentially important implications for today. First, institutions must be prepared for a 
policy change. In the case described above, the education system should have received additional funding before the policy change to prepare to absorb more and new types of students. This idea seems simple, but contemporary policy makers do not always appreciate it. The California Class Size Reduction (CCSR) program is a good example of this inadequate preparation (Bohrnstedt and Stecher 2002). In 1996, California mandated smaller class sizes for kindergarten through third grade. However, the state was not prepared with enough classrooms or qualified teachers, so students were learning in temporary classrooms with less qualified teachers. Qualified teachers also became less equally distributed, with unqualified teachers concentrated in schools with the most disadvantaged students. Thus even today, policies that could have important equalizing effects can actually exacerbate inequality due to inadequate planning and preparation. The unintended consequences found here and with the CCSR program remind us that evidence from a small-scale context may not scale up to the national level. Put simply, well-intentioned reforms can have unanticipated negative consequences (Apple 2008).

While the above example relates to elementary school, contemporary educational expansion efforts are concentrated at the postsecondary level in the United States and other developed countries. For example, President Obama's American Graduation Initiative seeks to increase college attendance and graduation. While my analysis of primary school expansion is not directly applicable to present-day U.S. efforts given the limitations mentioned above, the essential lesson about preparation may still prove useful to contemporary policy makers. Namely, postsecondary institutions should be properly funded and prepared for higher enrollment rates and new types of students prior to any expansion policies.

Second, results are relevant for the developing world, where many countries are working to achieve universal primary schooling. Raising the minimum level of schooling may not necessarily increase mobility. Furthermore, efforts to maintain school quality (e.g., through additional funding or schools) should accompany any increases in attendance to counteract potential crowding and disruption.

Where previous research has estimated the effect of education on individuals, the more complicated, nonlinear relationship found here could reflect the large-scale change. As existing research has found, educational expansion often initially increases inequality in education (Raftery and Hout 1993; Torche 2005; Paterson and Iannelli 2007). Building on that work, this study finds a similar effect of educational expansion with respect to intergenerational occupational mobility. In this case, however, the declining opportunity appears to have occured as a result of institutional inactivity rather elite efforts to maintain advantage. The evidence presented here of course represents a particular historical context. Additional research should 
American Journal of Sociology

investigate the relationship between education and mobility in other contexts. Overall, however, this historical evidence offers a pessimistic view of educational expansion as a mechanism to facilitate intergenerational mobility in the short term. While educational expansion undoubtedly carries other important benefits (e.g., for crime, health, and economic growth; Lochner and Moretti 2004; Lleras-Muney 2005; Lutz, Crespo Cuaresma, and Sanderson 2008), if the aim is equal occupational opportunity, education may not be an easy answer. At the very least, efforts to expand access to education should devote special attention to preparing for the policy change, with particular focus on early cohorts and disadvantaged families.

\section{APPENDIX}

Supplementary Analyses

\section{Analysis of Occupational Categories}

This sensitivity analysis uses log linear models to assess the degree of relative mobility experienced by sons on either side of the law after accounting for occupational change (absolute mobility) between the two generations. By dividing sons into categories based on years of school required, the log linear analysis comes closer to a causal estimate than most applications of this method and allows a nonlinear investigation by years of attendance required.

\section{Measure-Occupational Categories}

Ganzeboom et al. (1992) point out several advantages to continuous measures of occupational status and find that their international socioeconomic index compares favorably with the classic Erikson, Goldthorpe, and Portacarero (1979) scheme (EGP categories). Specifically, Ganzeboom et al. suggest that (1) some EGP categories are not internally homogeneous, with different mobility chances for some occupations in the same EGP category; (2) multivariate analysis is more feasible with continuous measures, which allows more informative results; and (3) log linear analyses can scale EGP categories on one dimension and measure class distance without much loss of information.

Nevertheless, there are equally important reasons to incorporate categorical analyses. First, as Ganzeboom et al. note, continuous measures may not deal adequately with immobility or absolute mobility. Specifically, continuous measures can hide the greater degree of immobility in specific categories (i.e., farmers and professionals); they treat immobility as just one variety of mobility rather than a distinct process; and there may be greater 
distinctions between some categories than a continuous measure would suggest. Second, sons of farmers make up a large proportion of the population in the late 1800s (approximately $50 \%$ of the sample) and greater mobility out of farming could swamp results for other groups if changes in the marginal occupational distribution are not adequately addressed (as Xie and Killewald [2010] argue). Third, occupational mobility research has long used occupational categories, partly to address distributional changes between generations. For all of these reasons, the relationship between early compulsory schooling laws and mobility is also investigated using occupational categories.

I assign occupations to categories based on the EGP classification system, which is widely used in social mobility studies (Hout 1989; Erikson and Goldthorpe 1992; Torche 2011). The EGP scheme classifies occupations according to how difficult it is for employers to monitor performance and how specific the required skills are (Goldthorpe 2000). Census occupation codes are translated to EGP categories using Morgan and Tang's (2007, especially pp. S10-S21) coding scheme, which has previously been used in mobility research (Torche 2011) and is based on a variety of sources. ${ }^{29}$ Like Morgan and Tang, I am unable to distinguish self-employed individuals or managers by how many workers they supervise. This analysis therefore excludes EGP category IV and may include more low-level managers than appropriate in EGP category I. The resulting categories include upper nonmanual, lower nonmanual, skilled manual, nonskilled manual, and agricultural occupations.

Table A1 provides descriptive statistics for each occupational category among fathers and (adult) sons by compulsory assignment. While the majority of fathers are in agriculture, there are only minor differences in father's occupation by son's compulsory school assignment. Thus, compulsory assignment is not related to father's occupation category. As adults, however, sons who were required to attend school are significantly less likely to be in an agriculture or nonskilled manual occupation and are significantly more likely to be in a nonmanual or skilled manual occupation. Figure A1 illustrates these distributions.

\section{Methods-Mobility Tables and Uniform Difference Models}

The uniform difference model (Erikson and Goldthorpe 1992; Xie 1992)— unidiff - can identify differences in the intergenerational association of

\footnotetext{
${ }^{29}$ Specifically, Morgan and Tang (2007) provide EGP categories for the 1980 and 1990 census occupation codes. The IPUMS Linked Representative Sample includes 1950 census occupation codes. I convert 1950 to 1990 census codes using the 1950 census, which includes standardized occupation codes for both 1950 and 1990, and then categorize the 1990 census codes appropriately based on Morgan and Tang (2007).
} 


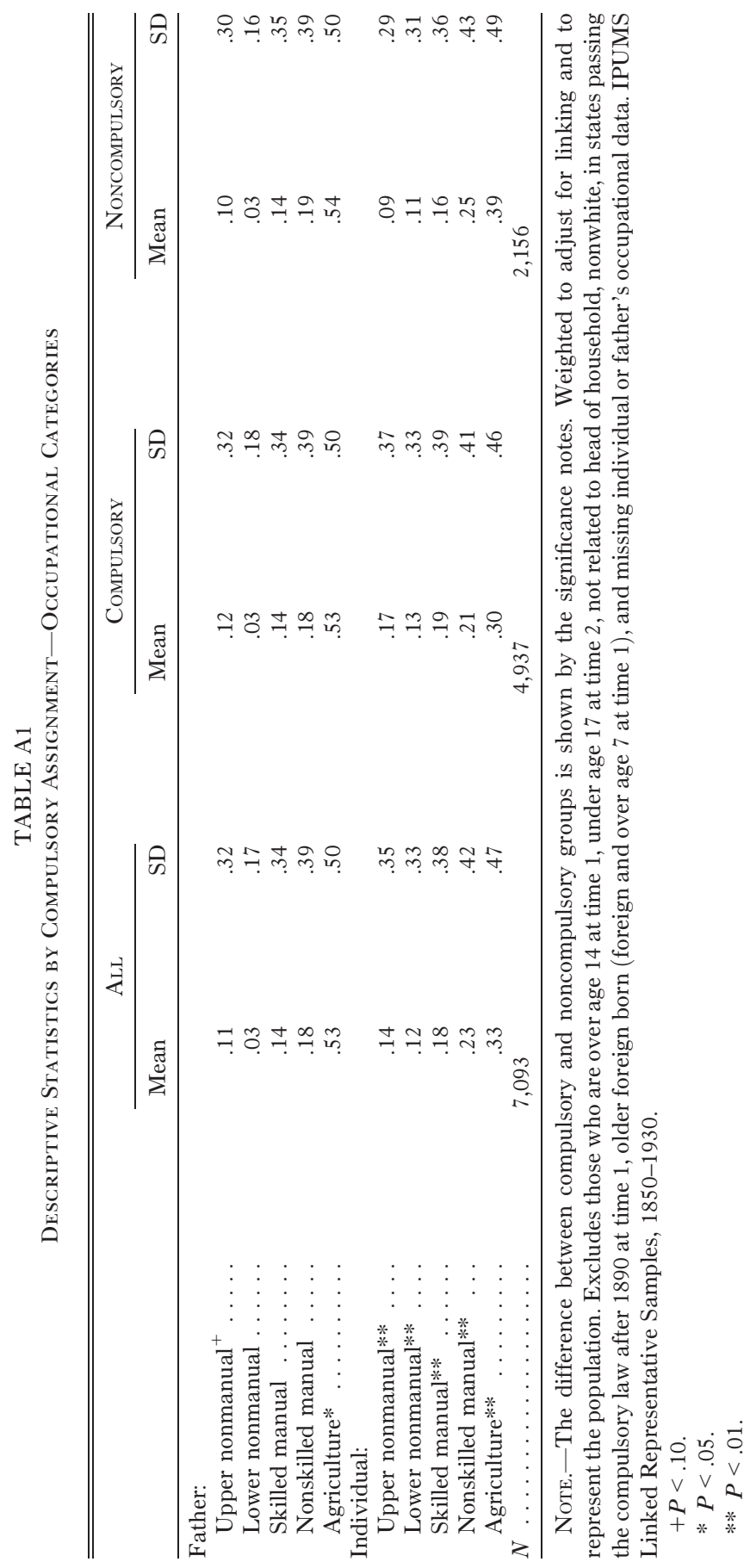

This content downloaded from 129.237.045.152 on May 04, 2017 09:59:46 AM All use subject to University of Chicago Press Terms and Conditions (http://www.journals.uchicago.edu/t-and-c). 


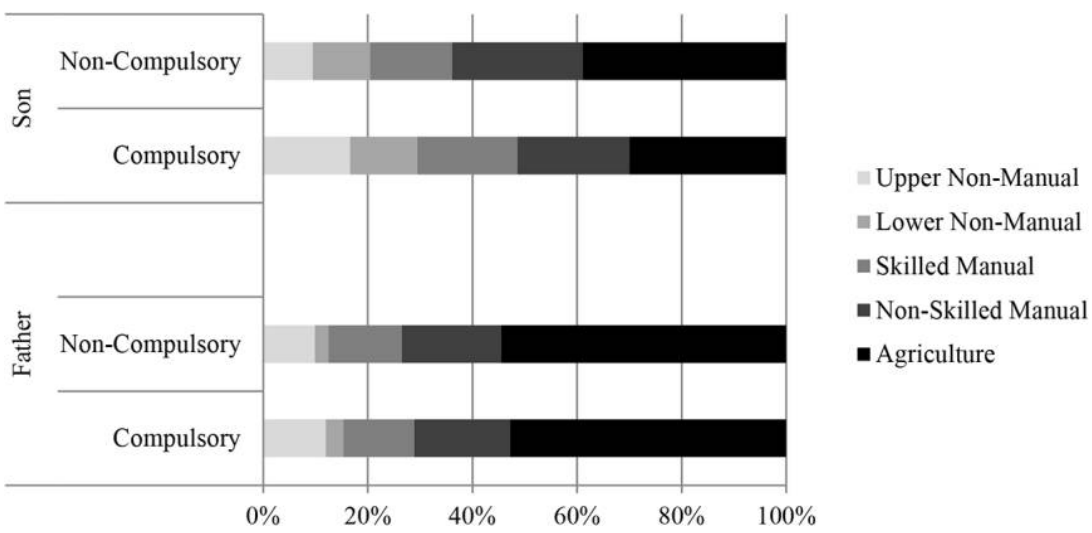

FIG. A1.-Distribution of occupational categories among fathers and sons. Based on table A1.

occupational categories by compulsory education. Unidiff classifies parental occupation by child occupation by compulsory category, hypothesizing that transmission is similar regardless of compulsory assignment. Various models are fit to the data, including full interaction (flexible but lacking parsimony), quasi-symmetry, and crossing models (treating occupations as differing in attainment difficulty). Each model is then unconstrained to assess whether occupational association varies by compulsory exposure. Most parsimoniously (Powers and Xie 2000, pp. 141-42), the unidiff effect model is

$$
F_{i j k}=\tau \tau_{i}^{R} \tau_{j}^{C} \tau_{k}^{L} \tau_{i k}^{R L} \tau_{j k}^{C L} \exp \left(\psi_{i j} \phi_{k}\right),
$$

where the $\tau$ parameters control for marginal effects for rows ( $\mathrm{R}$, father's EGP category), columns (C, child's EGP category), and layers (L, compulsory indicator), and their two-way interactions to best predict the number of observations in each father-son-layer category. The local log odds of attaining EGP category $j$ given parental EGP level $i$ for compulsory group $k$ is calculated as

$$
\log (\theta)_{i j \mid k}=\left(\psi_{i j}+\psi_{(i+1)(j+1)}-\psi_{i(j+1)}-\psi_{(i+1) j}\right) \phi_{k}=\phi_{k} \log \left(\theta_{i j}\right) .
$$

Bayesian information criteria (BIC) and likelihood ratio tests $\left(\mathrm{G}^{2}\right)$ are used to select the model best balancing data fit and parsimony (Raftery 1986, 1995). ${ }^{30}$

To investigate a nonlinear relationship, intergenerational association is allowed to vary by years of school required (in five-year intervals). Unidiff ${ }^{30} \mathrm{BIC}$ alone is insufficient because it may overvalue parsimony or simpler models (Weakliem 1999). 
models estimate the strength of association for those required to attend 6-10 years, 1-5 years, and zero years. If there is a nonlinear relationship, intergenerational association should be highest for those required to attend 1-5 years (the first group required to attend) and then decrease for those who had to attend longer.

Results

As Xie and Killewald (2010) note, continuous measures could mischaracterize occupational mobility, particularly given the high proportion of farming families in the late 1800s. Despite this concern, unidiff models of intergenerational occupational association by compulsory schooling support results using continuous measures. Including five years (birth cohorts) on each side of the compulsory cutoff, quasi-symmetry is the best-fitting model according to both explained deviance and the BIC statistic. Allowing mobility to vary by compulsory school assignment in a quasi-symmetry model, the father-son occupational association is slightly stronger among sons required to attend school. Results offer weak support, however; allowing association to vary by compulsory assignment does not yield a lower BIC statistic but does increase explained deviance and improves fit based on the likelihood ratio test.

Categorical analysis also suggests a nonlinear relationship between educational expansion and mobility. Figure A2 shows phi parameters by years of school required for the five best-fitting unidiff models according to $\mathrm{BIC}$ and deviance. ${ }^{31}$ Compared to those never required to attend and those required to attend for longer, the earliest group-required to attend school for just 1-5 years - had the strongest intergenerational association (the lowest occupational mobility). The later group, required to attend 6-10 years, experienced the lowest intergenerational association. All models show consistent results; the father-son association is greatest among those required to attend 1-5 years. The phi parameters depicted are scaled to one, which does not change the model (see Xie 1992, p. 382). When interpreting the parameters shown in figure A2, only the ratio is of interest, not the magnitude (Xie 1992). The figure shows parameters scaled to one because that makes it easier to interpret and compare across models. Thus, compared to those never required to attend, men required to attend for 1-5 years had $6 \%$ or $7 \%$ greater father-son occupational association, depending on the specific model. In turn, those required to attend for 6-10 years had 9\%-10\% lower father-son association (greater mobility) than those required to attend for

\footnotetext{
${ }^{31}$ The five best-fitting models are quasi-homogeneous row and column effects, quasisymmetry, quasi-crossing parameters, quasi-row and column effects, and full interaction/saturated. As fig. A2 shows, the results are not sensitive to model specification.
} 


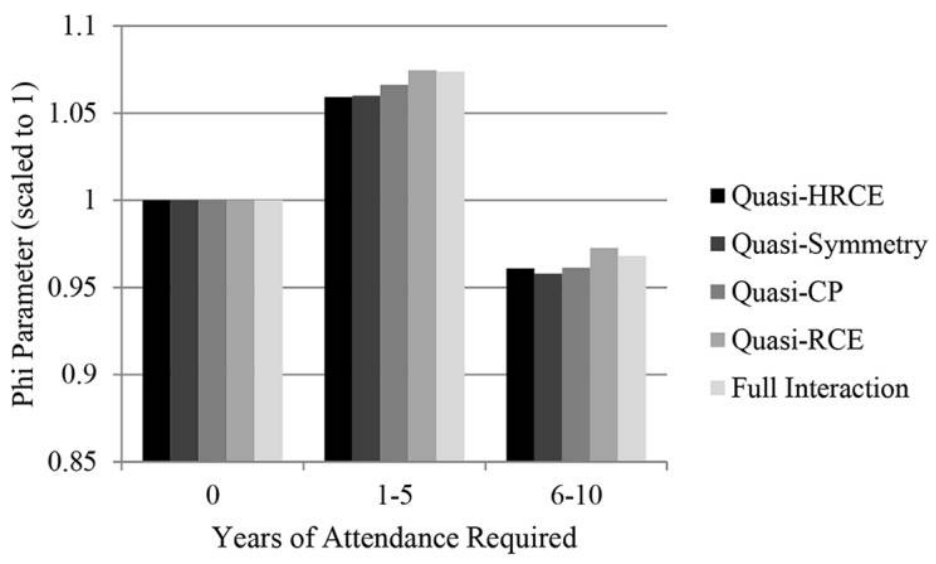

FIG A2.- Intergenerational association by years of required attendance- phi parameters. Data are from IPUMS Linked Representative Samples, 1850-1930. Weighted to adjust for linking and represent the population. Excludes those who are over age 14 at time 1, under age 17 at time 2, not related to head of household, nonwhite, in states passing the compulsory law after 1890 at time 1, older foreign born (foreign and over age seven at time 1), and missing individual or father's occupational data.

1-5 years. These results offer weak support, however, because allowing association to vary by compulsory assignment does not consistently improve model fit. ${ }^{32}$

To summarize, compulsory laws slightly reduced intergenerational mobility initially. However, continuous and categorical analyses both suggest a nonlinear relationship. Educational expansion reduced mobility for the earliest cohorts, who were required to attend school for only a few years, but increased it among later cohorts.

Analysis of Sibling Pairs

\section{Methods-Sibling Difference Analysis}

Some siblings appear in the linked data; they were living in the same household as children, had the same last name, and were related to the head of household as children. Given that brothers share family background, these siblings help identify compulsory education effects. Birth order is confounded with exposure to compulsory education, because those required to attend more years are always younger. However, sibling differences suggest whether compulsory education effects from other models are due to family

${ }^{32}$ Unidiff models (allowing intergenerational association to vary by age at the time of the law) do not yield a lower BIC statistic but slightly increase explained deviance and improve fit based on the likelihood ratio test (though insignificantly). 
factors. Elder brother SEI score minus younger brother SEI score measures elder brother advantage. On average, elder brothers achieved higher SEI scores than younger siblings. Presumably, compulsory education should allow more equal occupational attainment between older and younger brothers. Therefore, if compulsory assignment increased sibling SEI difference, it would suggest that younger brothers experienced less mobility (less equal opportunity) from compulsory schooling. A decrease in sibling SEI difference would suggest that compulsory assignment increased mobility.

Analysis is conducted at the sibling pair level. Difference in sibling occupational SEI attainment is regressed on difference in years of schooling required and its square, controlling for age differences. Because of the small number of brother pairs in which the older brother never had to attend school and the younger $\operatorname{did}(N=22$ pairs $)$, this is an ancillary analysis and controls are limited, but results should echo those from the main analysis.

Results

The same nonlinear relationship appears in the analysis of sibling pairs. The main effect for difference in years required is insignificant. However, adding a squared term makes them both significant, and model fit statistics (BIC, AIC, and log likelihood) all suggest that the squared term offers a significant improvement in model fit. Figure A3 shows the nonlinear relationship in predicted sibling SEI differences, and table A2 provides the regression results. Status attainment or industrialization theory might expect a steady decline in elder brother advantage as younger brothers are required to attend additional years of school. Instead, elder brother advantage is greatest when the younger brother had to attend a few years and lowest when the younger brother had to attend the maximum number of years.

State-Level Analysis

\section{Measures}

State-level school attendance rates are calculated at each census year using the regular census data. Separate state attendance rates are calculated among school-age boys with low-SEI fathers (less than 14), high-SEI fathers (above 14), and farm fathers (SEI of 14). This cut point is chosen because sons of farmers make up about half of the linked sample and, given high mobility out of agriculture around the turn of the century (Xie and Killewald 2010), constitute a distinct group. Farmers have an SEI score of 14 , so that cutoff is chosen for the low and high SEI categories. 


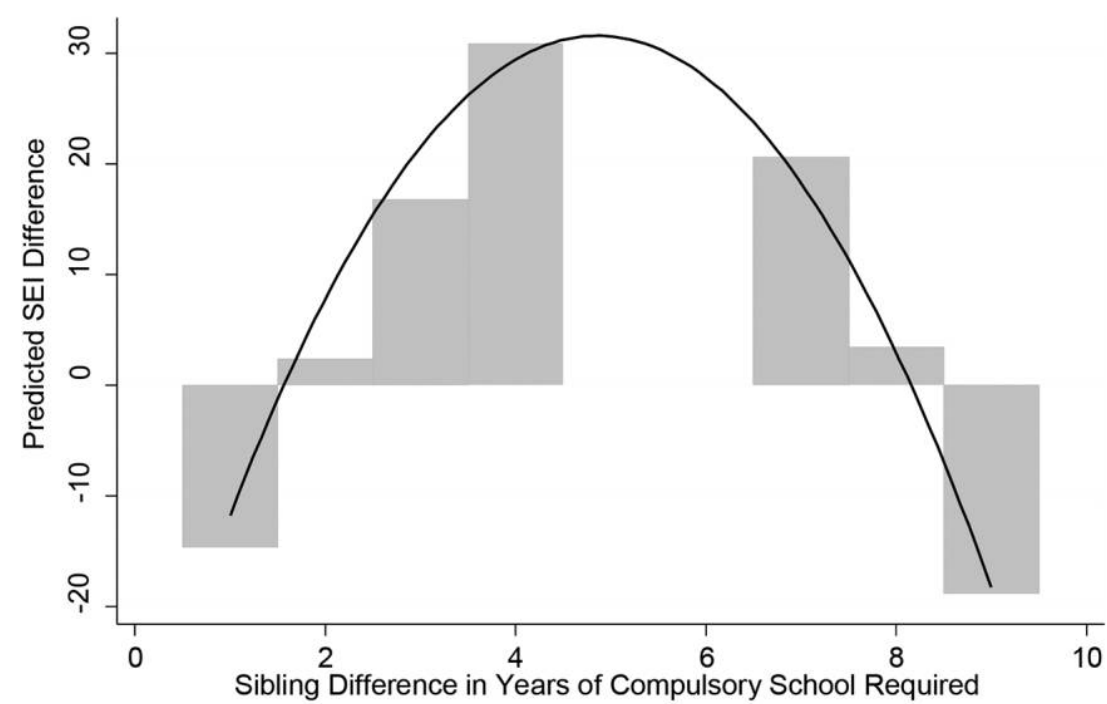

Predicted SEI Difference - net age diff Fitted values

FIG. A3.-Predicted sibling SEI differences by difference in required schooling. Predicted sibling difference in SEI scores (elder brother minus younger brother) by difference in years of required schooling. Sample is limited to brother pairs who differed in compulsory assignment. Coefficients and standard errors are shown in table A2. Data are from IPUMS Linked Representative Samples, 1850-1930.

Sons of fathers with SEI scores below 14 represent about $14 \%$, while $33 \%$ are above 14 .

\section{Methods}

With indicators for each state $\left(u_{i}\right)$ and year $\left(\lambda_{j}\right)$ included, equation (A3) estimates whether, compared to high-SEI boys, compulsory laws increased attendance more for boys from farm and low-SEI backgrounds.

$$
\begin{aligned}
\text { Attendance Rate }_{i j k}= & \alpha+\text { DadOcc Category }_{k}+\beta_{1} \text { CompSchool }_{i j k} \\
& +\beta_{2 k} \text { CompSchool }_{i j k} \times \text { DadOcc Category }_{k} \\
& +\beta_{3} \mathrm{X}_{i j k}+u_{i}+\lambda_{j}+\varepsilon_{i j k} .
\end{aligned}
$$

Indicators for father's occupational category are interacted with a compulsory school measure indicating whether attendance was compulsory in a state at each census year. High SEI is the omitted category, so if compulsory laws increased attendance more for lower-SEI youth, the two $\beta_{2}$ coefficients should be positive and significant. Controls (represented by $X$ ) include the same state-level controls included in the individual analysis. 
American Journal of Sociology

TABLE A2

Sibling Differences in SEI Scores

\begin{tabular}{|c|c|c|}
\hline \multirow[b]{2}{*}{ VARIABLE } & \multicolumn{2}{|c|}{ Sibling SEI Difference } \\
\hline & Coefficient & $\mathrm{SE}$ \\
\hline Diff in years required . . . . . & 28.44 & $10.34 *$ \\
\hline Diff in years required ${ }^{2}$ & -3.04 & $.98 * *$ \\
\hline Age difference $\ldots \ldots \ldots \ldots$ & 1.61 & 1.02 \\
\hline Constant . . . . . . . . . & -48.72 & $21.04 *$ \\
\hline$R^{2}$ & .32 & \\
\hline$N$ sibling pairs $\ldots \ldots \ldots \ldots$ & 22 & \\
\hline
\end{tabular}

Note.-Predicted sibling difference in SEI scores (elder brother minus younger brother) by difference in years of required schooling. Sample is limited to brothers who differed in compulsory assignment. Data are form IPUMS Linked Representative Samples, 1850-1930.

$* P<.05$.

** $P<.01$

To investigate the relationship between the laws and mobility, statelevel father-son SEI correlation is calculated at each census year. This measure of mobility is regressed on an indicator for whether the state had passed a compulsory law yet, with indicators for each state $\left(u_{i}\right)$ and year $\left(\lambda_{j}\right)$, and the same state controls as those in equations (1) and (2). The coefficient for compulsory school in equation (A4) measures whether mobility differs before and after the law.

$$
\begin{aligned}
\text { Father-Son SEI Correlation }_{i j}= & \alpha+\beta_{1} \text { CompSchool }_{i j} \\
& +\beta_{2} \mathrm{X}_{i j}+u_{i}+\lambda_{j}+\varepsilon_{i j} .
\end{aligned}
$$

Results

Table A3 provides state attendance rates by SEI category and compulsory law. The final column compares the difference in attendance before and after the compulsory law by SEI category. At the descriptive level, these differences show that state attendance rates increased at all SEI levels, but they increased the most among low-SEI boys. State-level regressionmodel 1 in table A4-provides similar evidence of an equalizing effect. Net of state and census year differences, the compulsory law interaction with the low-SEI category is positive and significant. This suggests that, compared to higher-SEI boys, compulsory laws increased attendance more among boys from low-SEI backgrounds.

State-level attendance rates differ from the individual-level school attendance data (descriptive statistics shown in table 2 of the main text) partly because the state data include more years and cohorts and partly because of the unequal likelihood of appearing in the linked data by age or cohort. In 


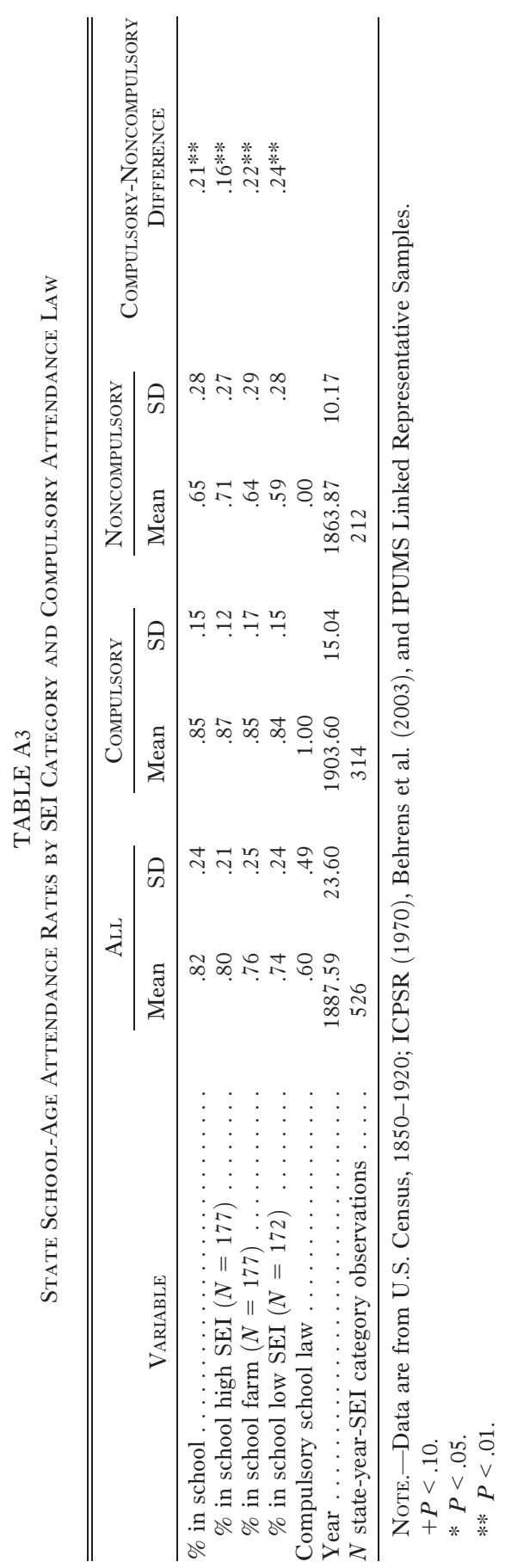

This content downloaded from 129.237.045.152 on May 04, 2017 09:59:46 AM All use subject to University of Chicago Press Terms and Conditions (http://www.journals.uchicago.edu/t-and-c). 


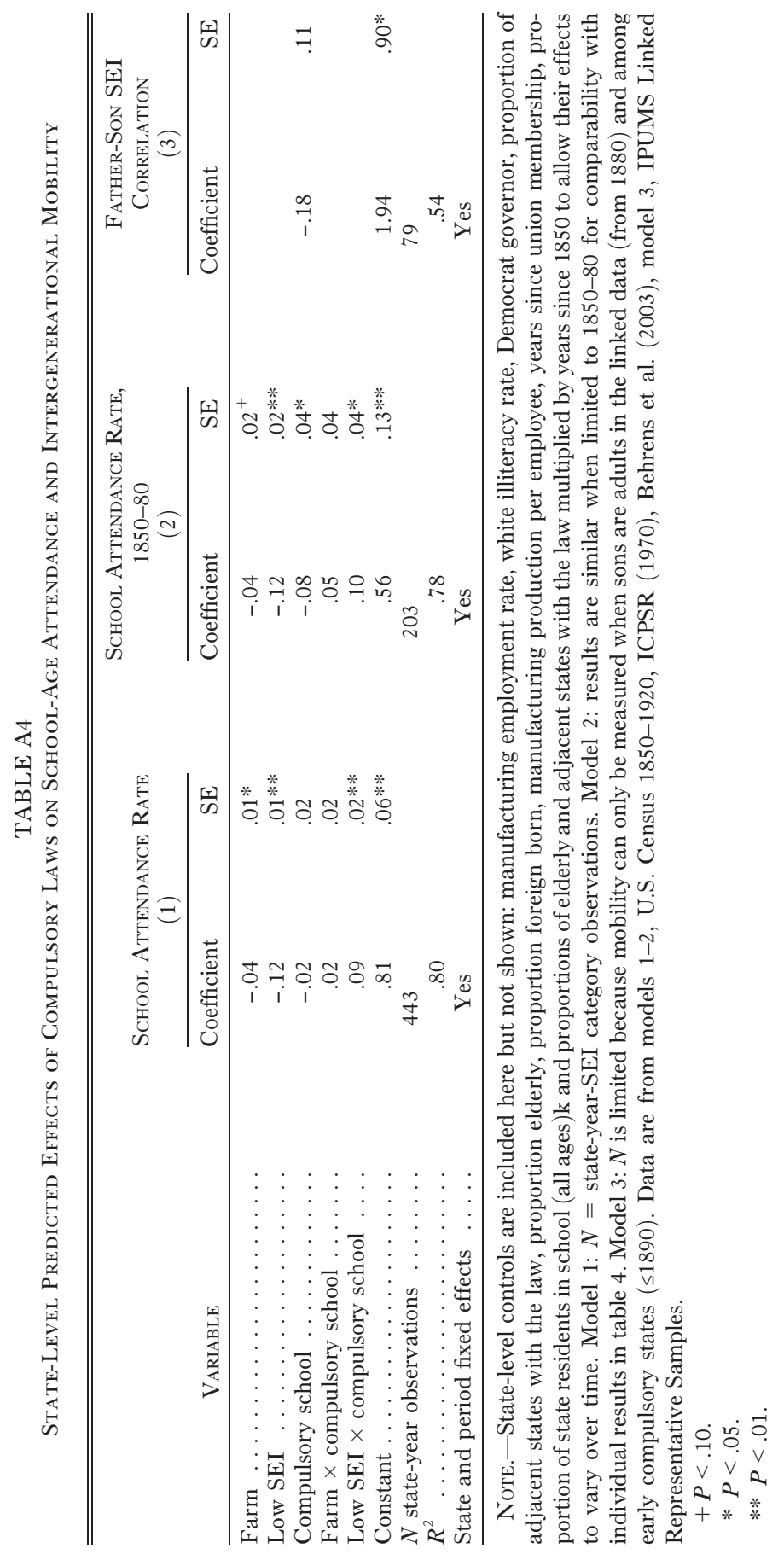

This content downloaded from 129.237.045.152 on May 04, 2017 09:59:46 AM All use subject to University of Chicago Press Terms and Conditions (http://www.journals.uchicago.edu/t-and-c). 
addition to missing attendance data for many of those observed as children in 1880, the linked data are limited to those born before 1881 and only provide valid school attendance information among those who happen to be age $8-13$ at the first census observation, which eliminates anyone born after 1873. To make the state-level attendance analyses more comparable to the sample in the individual-level linked data (and individual attendance results in table 4 above), I repeated the state-level attendance analyses based only on years 1850-80 and found similar results (shown in table A4).

Despite this equalizing effect on attendance, state-level analyses suggest that the laws did not increase mobility. Model 3 in table A4 shows that, net of state and year differences, the intergenerational SEI association is lower after the compulsory laws. However, this relationship is not significant. In other words, mobility may have increased as a result of the compulsory laws, but the difference is not significantly different from zero.

Analyzing nonlinear effects on mobility at the state level is difficult because it is only possible to measure state mobility (father-son correlation) each 10 years. Furthermore, sons must be adults in the linked census, which limits state mobility data to censuses after 1870, and only states with early compulsory laws in or before 1890 are examined here. Combined with some states having too few sons in the linked data for valid correlation measures, this yields only six states with mobility information before the law (those with compulsory laws 1880-90). (The small number of state mobility observations before the law could explain the null relationship with mobility found in model 3 of table A4.) Most important, state characteristics are confounded with time since the law because a state was often the only one to pass a law in a given year. These data limitations would make state-level nonlinear analysis untrustworthy, and it is not pursued here.

Regression Discontinuity Graphs

Graphs by the forcing variable: Compulsory cohort.-In all graphs (figs. A4A7), compulsory cohort is centered at the cutoff so individuals in the range -10 to -1 were required to attend school and those in the range 0 to 9 were never required to attend. 


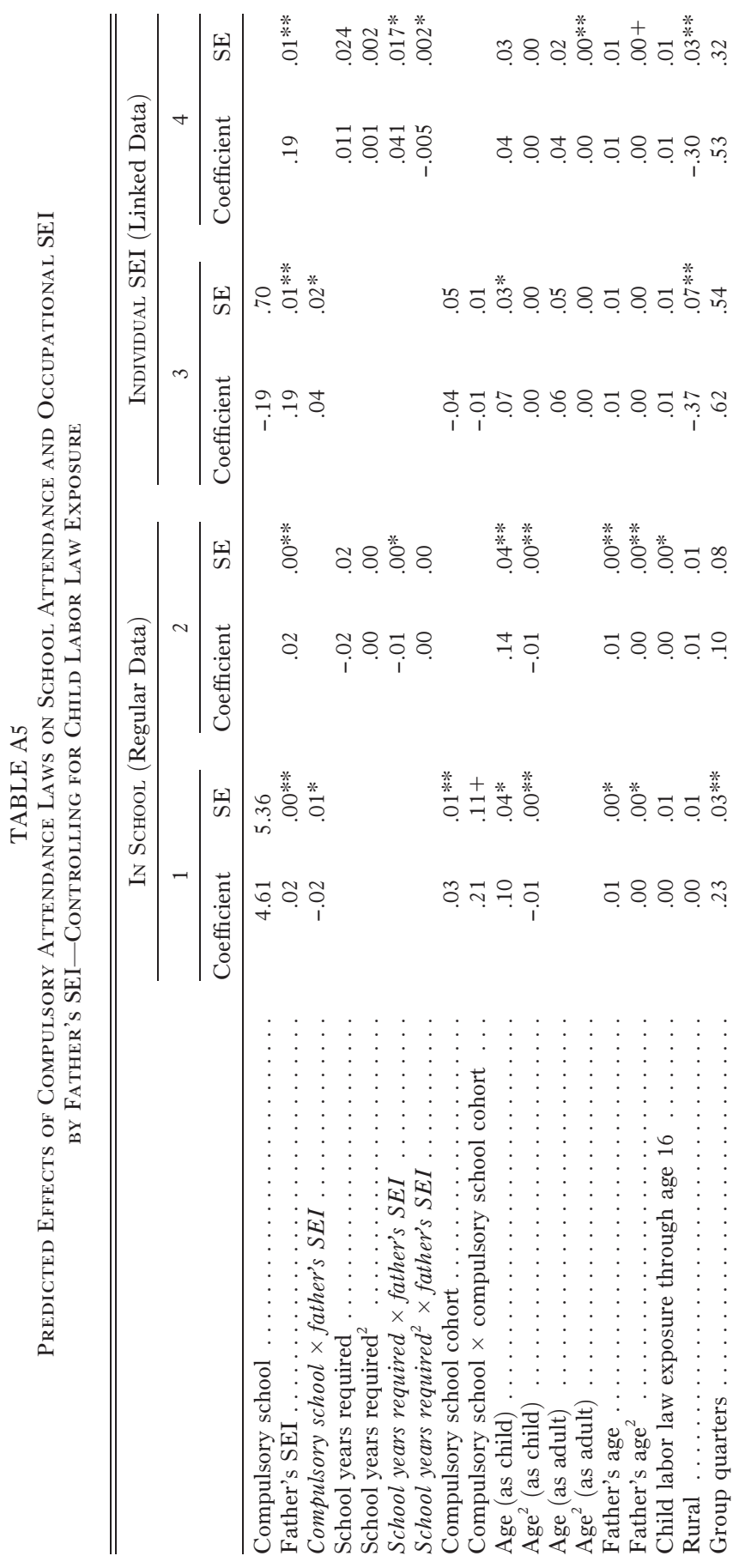

1752 


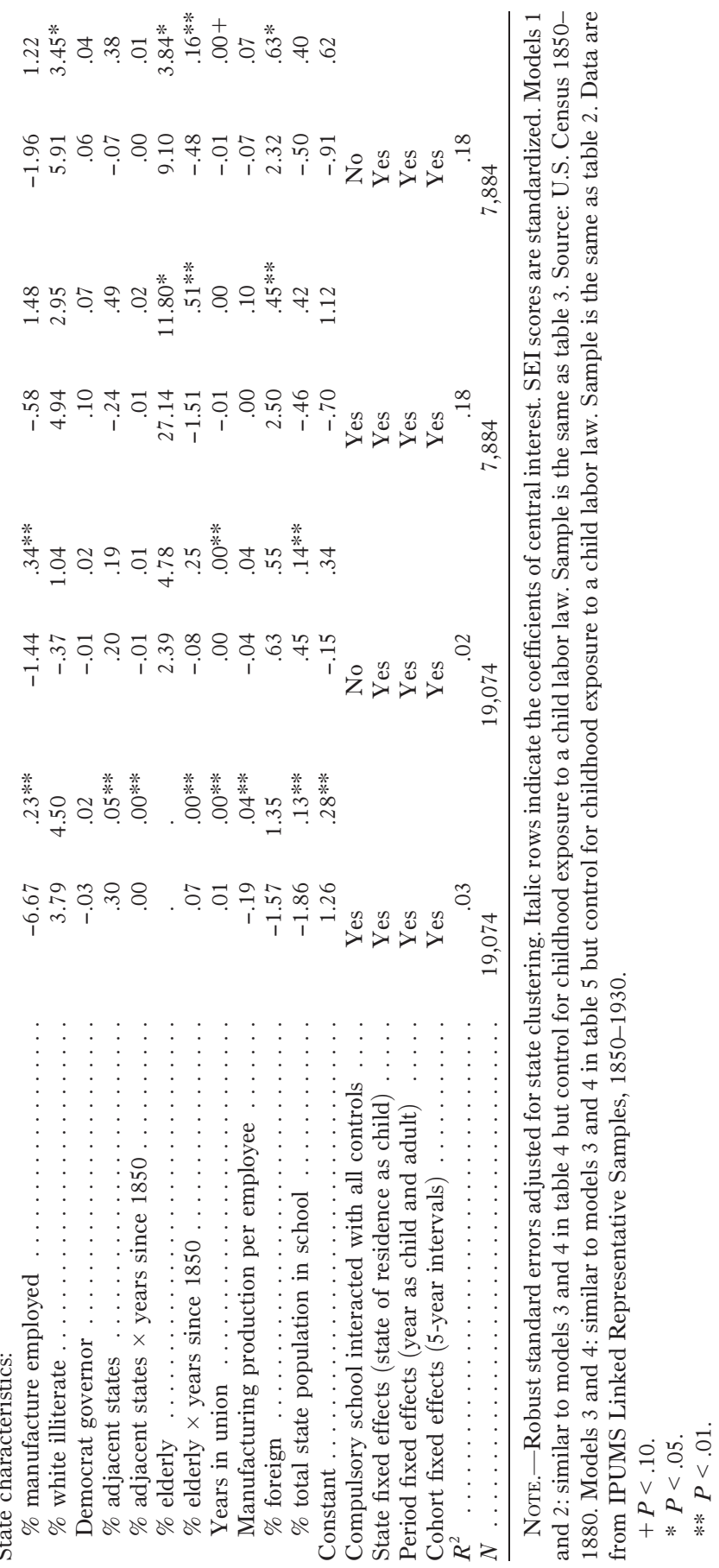

1753

This content downloaded from 129.237.045.152 on May 04, 2017 09:59:46 AM 


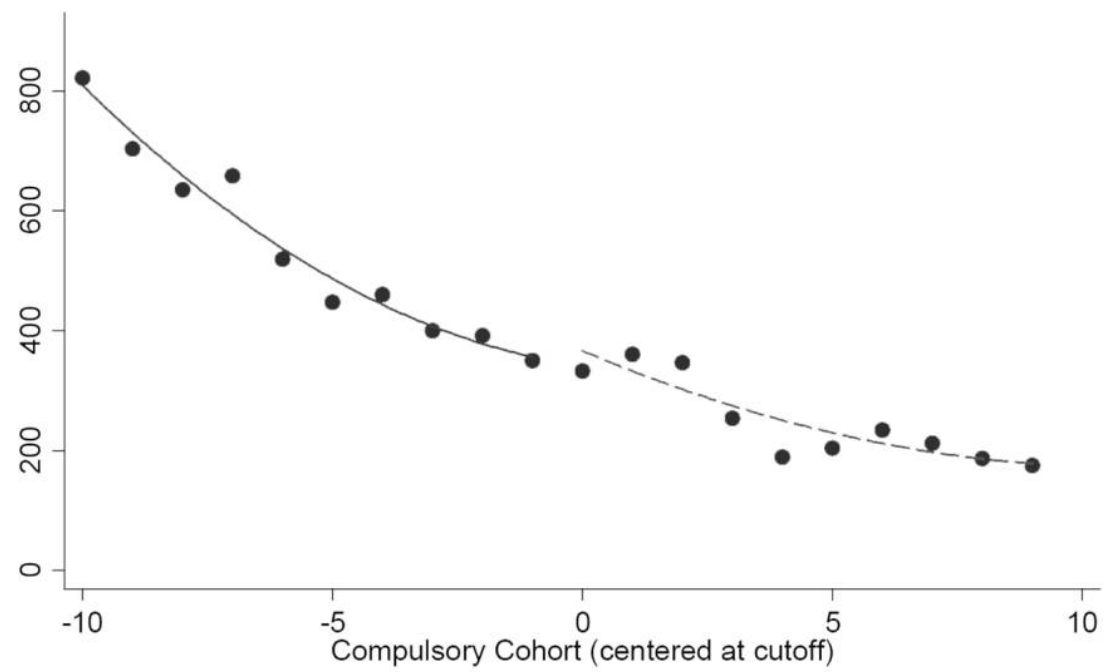

- Frequency

Required to Attend School Never Required to Attend School

FIG. A4.-Frequency (number of observations in the sample)

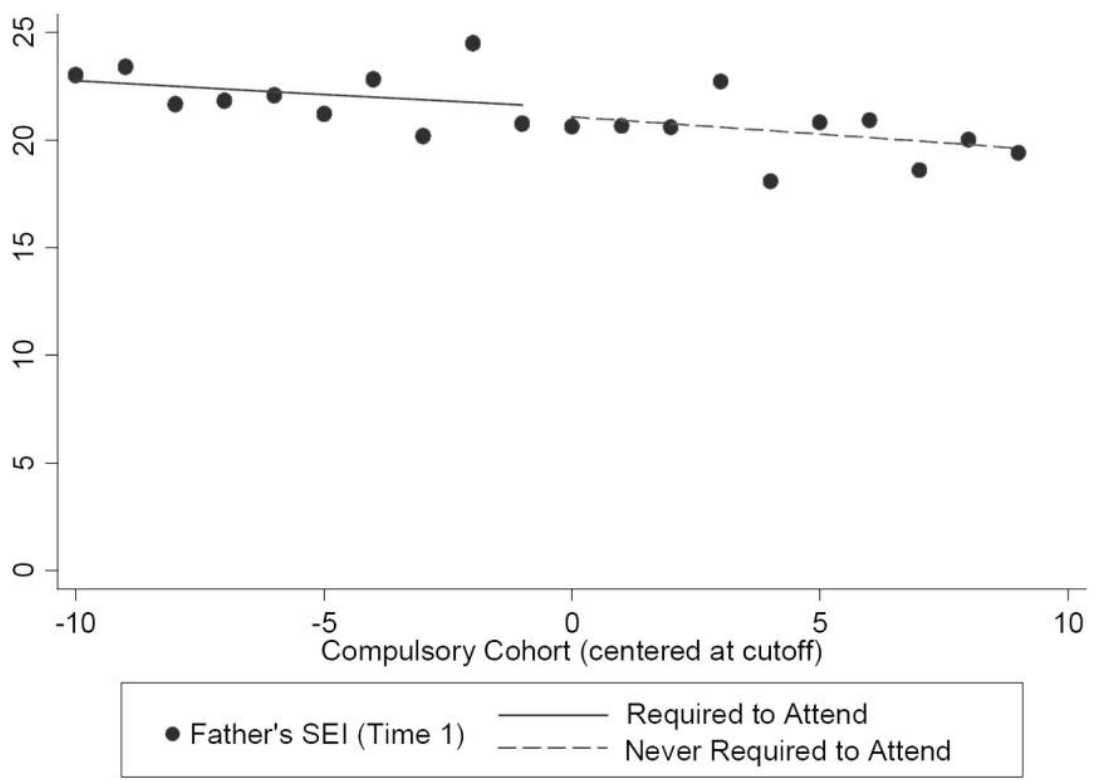

FIG. A5.-Father's SEI at time 1

1754 


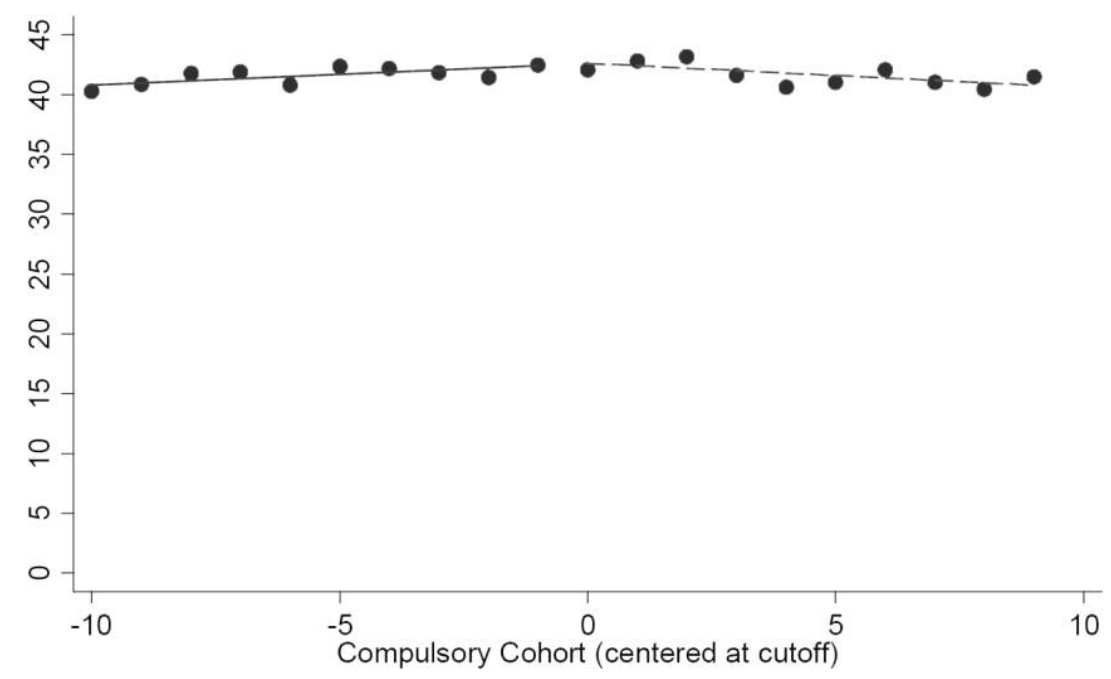

- Father's Age (Time 1)

Required to Attend Never Required to Attend

FIG. A6.-Father's age at time 1

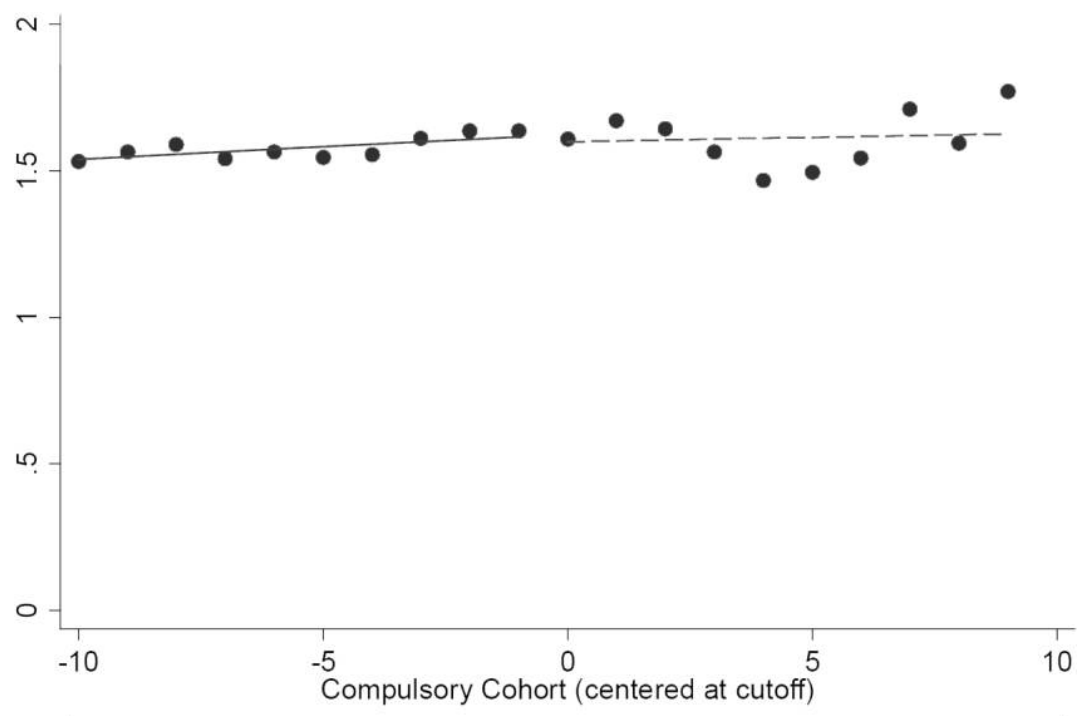

State Manuf Prod per Empl (Time 1)

Required to Attend Never Required to Attend

FIG. A7.- State manufacturing production per employee at time 1

1755

This content downloaded from 129.237.045.152 on May 04, 2017 09:59:46 AM

All use subject to University of Chicago Press Terms and Conditions (http://www.journals.uchicago.edu/t-and-c). 


\section{American Journal of Sociology}

\section{REFERENCES}

Acemoglu, Daron. 2010. "Theory, General Equilibrium and Political Economy in Development Economics." Journal of Economic Perspectives 24 (3): 17-32.

Acemoglu, Daron, and Simon Johnson. 2007. "Disease and Development: The Effect of Life Expectancy on Economic Growth." Journal of Political Economv 115:92585 .

Angrist, Joshua D. 1995. "The Economic Returns to Schooling in the West Bank and Gaza Strip.”American Economic Review 85:1065-87.

Angrist, Joshua D., Guido W. Imbens, and Donald B. Rubin. 1996. "Identification of Causal Effects Using Instrumental Variables." Journal of the American Statistical Association 91 (434): 444-55.

Angrist, Joshua D., and Alan B. Krueger. 1991. "Does Compulsory School Attendance Affect Schooling and Earnings?” Quarterly Journal of Economics 106 (4): 979-1014.

Apple, Michael. 2008. "Can Schooling Contribute to a More Just Society?" Education. Citizenship and Social Justice 3 (3): 239-61.

Archer, Margaret. 1979. The Social Origins of Educational Systems. Beverly Hills, Calif.: Sage.

Attewell, Paul, and David E. Lavin. 2007. Passing the Torch: Does Higher Education for the Disadvantaged Pay Off across the Generations? New York: Russell Sage.

Ayres, Leonard P. 1909. Laggards in Our Schools: A Study of Retardation and Elimination in City School Systems. New York: Russell Sage.

Baker, David P. 1999. "Schooling All the Masses: Reconsidering the Origins of American Schooling in the Postbellum Era." Sociology of Education 72 (4): 197-215.

Becker, Gary S. 1964. Human Capital: A Theoretical and Empirical Analysis, with Special Reference to Education. Chicago: University of Chicago Press.

Becker, Gary S., and Nigel Tomes. 1994. "Human Capital and the Rise and Fall of Families.” Pp. 257-98 in Human Capital: A Theoretical and Empirical Analysis with Special Reference to Education, by Gary S. Becker. 3d ed. Chicago: University of Chicago Press.

Behrens, Angela, Christopher Uggen, and Jeff Manza. 2003. "Ballot Manipulation and the 'Menace of Negro Domination': Racial Threat and Felon Disenfranchisement in the United States, 1850-2002.” American Journal of Sociology 109:559-605.

Beller, Emily, and Michael Hout. 2006. "Intergenerational Social Mobility: The United States in Comparative Perspective." Future of Children 16 (2): 19-36.

Berg, Ivar. 1971. Education and Jobs: The Great Training Robbery. Boston: Beacon.

Bjorklund, Anders, and Markus Jantti. 2000. "Intergenerational Mobility of Socioeconomic Status in Comparative Perspective." Nordic Journal of Political Economy 26 (1): 3-33.

Blau, Peter M., and Otis Dudley Duncan (with Andrea Tyree). 1967. The American Occupational Structure. New York: Wiley.

Bohrnstedt, George W., and Brian M. Stecher, eds. 2002. What We Have Learned about Class Size Reduction in California. Sacramento: California Department of Education. www.classize.org/techreport/CSRYear4_final.pdf.

Boudon, Raymond. 1974. Education, Opportunity, and Social Inequality. New York: Wiley.

Bowles, Samuel, and Herbert Gintis. 1976. Schooling in Capitalist America: Educational Reform and the Contradictions of Economic Life. New York: Basic.

Breen, Richard. 2010. "Educational Expansion and Social Mobility in the 20th Century." Social Forces 89 (2): 365-88.

Breen, Richard, and Jan O. Jonsson. 2005. "Inequality of Opportunity in Comparative Perspective: Recent Research on Educational Attainment and Social Mobility.” $\underline{A}$ nual Review of Sociology 31:223-43. 
Brunello, Giorgio, Margherita Fort, and Guglielmo Weber. 2009. "Changes in Compulsory Schooling, Education, and the Distribution of Wages in Europe." Economic Journal 119 (536): 516-39.

Carlson, Robert A. 1975. The Quest for Conformity: Americanization through Education. New York: Wiley \& Sons.

Cheung, Hoi Yan, and Alex W. Chan. 2008. "Understanding the Relationships among PISA Scores, Economic Growth and Employment in Different Sectors." Research in Education 80:93-106.

Collins, Randall. 1971. "Functional and Conflict Theories of Educational Stratification." American Sociological Review 36:1002-19.

Conk, Margo Anderson. 1978. "Occupational Classification in the United States Census: 1870-1940." Journal of Interdisciplinarv History 9 (1): 111-30.

Cunha, Flavio, James J. Heckman, and Salvador Navarro. 2006. "Counterfactual Analysis of Inequality and Social Mobility." In Mobility and Inequality: Frontiers of Research from Sociology and Economics, edited by S. Morgan, D. Grusky, and G. Fields. Palo Alto, Calif.: Stanford University Press.

Cutler, William W., III. 1989. "Cathedral of Culture: The Schoolhouse in American Educational Thought and Practice since 1820." History of Education Quarterly 29 (1): $1-40$.

Edwards, Linda Nasif. 1978. "An Empirical Analysis of Compulsory Schooling Legislation, 1940-1960." Journal of Law and Economics 21:203-22.

Erikson, Robert, and John H. Goldthorpe. 1992. The Constant Flux: A Study of Class Mobility in Industrial Societies. Oxford: Clarendon.

Erikson, Robert, John H. Goldthorpe, and Lucianne Portocarero. 1979. "Intergenerational Class Mobility in Three Western European Societies: England, France, and Sweden." British Journal of Sociology 30:415-30.

Featherman, David L., and Robert M. Hauser. 1978. Opportunity and Change. New York: Academic Press.

Ferrie, Joseph P. 2005. "History Lessons: The End of American Exceptionalism? Mobility in the United States since 1850." Journal of Economic Perspectives 19 (3): 199215 .

Field, Alexander James. 1976. "Educational Expansion in Mid-nineteenth Century Massachusetts." Harvard Educational Review 46 (November): 521-52.

Freedman, David A. 2006. "Statistical Models for Causation: What Inferential Leverage Do They Provide?" Evaluation Review 30 (6): 691-713.

Ganzeboom, Harry B. G., Paul M. DeGraaf, Donald J. Treiman, and Jan de Leeuw. 1992. "A Standard International Socio-Economic Index of Occupational Status." Social Science Research 21:1-56.

Goldin, Claudia. 1999. "Egalitarianism and the Returns to Education during the Great Transformation of American Education." Journal of Political Economv 107: S65-S94.

Goldin, Claudia, and Lawrence F. Katz. 2008. The Race between Education and Technology. Cambridge, Mass.: Harvard University Press.

_ 2011. "Mass Secondary Schooling and the State: The Role of State Compulsion in the High School Movement." In Understanding Long-Run Economic Growth, edited by D. Costa and N. Lamoreaux. Chicago: University of Chicago Press.

Goldthorpe, John H. 2000. On Sociology: Numbers, Narratives, and the Integration of Research and Theory. Oxford: Oxford University Press.

Granovetter, Mark. 1973. "The Strength of Weak Ties." American Journal of Sociology 78 (6): 1360-80.

Grawe, Nathan. 2008. "Education and Economic Mobility." Urban Institute, PEW Charitable Trust, Washington, D.C.www.urban.org/url.cfm?ID $=1001157$.

. 2010. "Primary and Secondary School Quality and Intergenerational Earnings Mobility." Journal of Human Capital 4 (4): 331-64. 


\section{American Journal of Sociology}

Grusky, David. 1983. "Industrialization and the Status Attainment Process: The Thesis of Industrialism Reconsidered." American Sociological Review 48 (4): 494-506.

Haider, Steven, and Gary Solon. 2006. "Life-Cycle Variation in the Association between Current and Lifetime Earnings." American Economic Review 96 (4): 1308-20.

Hanushek, Eric, and Ludger Woessmann. 2009. "Do Better Schools Lead to More Growth? Cognitive Skills, Economic Outcomes, and Causation.” NBER Working paper no. 14633, National Bureau of Economic Research, Cambridge, Mass.

Hauser, Robert. 1998. "Intergenerational Economic Mobility in the United States: Measures, Differentials, and Trends." Working paper 98-12, University of WisconsinMadison, Center for Demography and Ecology.

Hong, Guanglei, and Stephen W. Raudenbush. 2006. "Evaluating Kindergarten Retention Policy: A Case Study of Causal Inference for Multilevel Observational Data." Journal of American Statistical Association 101 (474): 901-10.

Hout, Michael. 1984. "Status, Autonomy, and Training in Occupational Mobility." American Journal of Sociology 89 (6): 1397-1409. 1988. "More Universalism, Less Structural Mobility: The American Occupational Structure in the 1980s." American Journal of Sociologv 93:1358-1400.

. 1989. Following in Father's Footsteps: Social Mobility in Ireland. Cambridge, Mass.: Harvard University Press.

ICPSR (Inter-university Consortium for Political and Social Research). 1970. Historical, Demographic, Economic, and Social Data: The United States, 1790-1970 [Computer file]. Ann Arbor, Mich.: ICPSR.

Imbens, Guido W., and Thomas Lemieux. 2008. "Regression Discontinuity Designs: A Guide to Practice." Journal of Econometrics 142:615-35.

Jantti, Markus, Bernt Bratsberg, Knut Roed, Oddbjorn Raaum, Robin Naylor, Eva Osterbacka, and Tor Eriksson. 2006. "American Exceptionalism in a New Light: A Comparison of Intergenerational Earnings Mobility in the Nordic Countries, the United Kingdom and the United States.” Institute for the Study of Labor (IZA) Discussion paper no. 1938, Bonn.

Jencks, Christopher, and Laura Tach. 2006. "Would Equal Opportunity Mean More Mobility?" Chap. 2 in Mobility and Inequality, edited by S. Morgan, D. Grusky, and G. Fields. Palo Alto, Calif.: Stanford University Press.

Kaelble, Hartmut. 1981. Historical Research on Social Mobility: Western Europe and the USA in the Nineteenth and Twentieth Centuries. London: Croom Helm.

- 1986. Social Mobility in the 19th and 20th Centuries: Europe and America in Comparative Perspective. New York: St. Martin's.

Kaestle, Carl F. 1983. Pillars of the Republic: Common Schools and American Society, 1780-1860. New York: Hill \& Wang.

Katz, Michael B. 1968. The Irony of Early School Reform: Educational Innovation in Mid-nineteenth Century Massachusetts. Cambridge, Mass.: Harvard University Press.

Katz, Michael S. 1976. A History of Compulsory Education Laws. Fastback Series, 75. Bicentennial Series. Bloomington, Ind.: Phi Delta Kappa.

Kotin, Lawrence, and William F. Aikman. 1980. Legal Foundations of Compulsory School Attendance. Port Washington, N.Y.: Kennikat.

Landes, William M., and Lewis C. Solmon. 1972. "Compulsory Schooling Legislation: An Economic Analysis of Law and Social Change in the Nineteenth Century." Journal of Economic History 32 (1): 54-91.

Lassonde, Stephen. 1996. "Learning and Earning: Schooling, Juvenile Employment, and the Early Life Course in Late Nineteenth-Century New Haven." Journal of Social Historv 29 (4): 839-70.

Lee, David S., and David Card. 2008. "Regression Discontinuity Inference with Specification Error." Journal of Econometrics 142:655-74.

Lee, David S., and Thomas Lemieux. 2010. "Regression Discontinuity Designs in Economics." Journal of Economic Literature 48:281-355. 
Li, Hongyi, and Liang Huang. 2009. "Health, Education, and Economic Growth in China: Empirical Findings and Implications." China Economic Review 20 (3): 37487.

Lleras-Muney, Adriana. 2005. "The Relationship between Education and Adult Mortality in the United States." Review of Economic Studies 72:189-221.

Lochner, Lance, and Enrico Moretti. 2004. "The Effect of Education on Crime: Evidence from Prison Inmates, Arrests, and Self-Reports." American Economic Review 94 (1): 155-89.

Loughran, Miriam E. 1921. "The Historical Development of Child-Labor Legislation in the United States." Ph.D. dissertation, Catholic University of America. http://www .archive.org/details/historicaldevel00louggoog

Lucas, Samuel R. 2001. "Effectively Maintained Inequality: Education Transitions, Track Mobility, and Social Background Effects." American Journal of Sociology 106: 1642-90.

Lutz, Wolfgang, Jesus Crespo Cuaresma, and Warren Sanderson. 2008. "The Demography of Educational Attainment and Economic Growth." Science 319 (5866):104748.

Mann, Horace. 1849. Twelfth Annual Report of the Board of Education. Boston: Dutton \& Wentworth.

Mazumder, Bhashkar. 2005. "Fortunate Sons: New Estimates of Intergenerational Mobility in the U.S. Using Social Security Earnings Data." Review of Economics and Statistics 87235-55.

McAfee, Ward M. 1998. Religion, Race, and Reconstruction: The Public School in the Politics of the 1870s. Albany: State University of New York Press.

McCrary, Justin. 2008. "Manipulation of the Running Variable in the Regression Discontinuity Design: A Density Test." Journal of Econometrics 142 (2): 698-714.

Meyer, John W., Francisco O. Ramirez, and Yasemin Nuhoglu Soysal. 1992. "World Expansion of Mass Education, 1870-1980.” Sociology of Education 65 (2): 128-49.

Meyer, John W., David Tyack, Joane Nagel, and Audri Gordon. 1979. "Public Education as Nation-Building in America: Enrollments and Bureaucratization in the American States, 1870-1930." American Journal of Sociology 85 (3): 591-613.

Milner, Murray J. 1972. The Illusion of Equality: The Effect of Education on Opportunity, Inequality, and Social Conflict. San Francisco: Jossey-Bass.

Moore, Ernest Carroll. 1902. "The Effect of Compulsory Education upon the Poor." Western Journal of Education 7 (6): 339-45.

Morgan, Stephen L., and Zun Tang. 2007. "Social Class and Workers' Rent: 19832001." Research in Social Stratification and Mobility 25:273-93.

New York Times. 1877. "The Schools of the City." New York Times, March 7.

_. 1878. "Public Schools." New York Times, October 2.

Oreopoulos, Philip. 2006. "Estimating Average and Local Average Treatment Effects When Compulsory Schooling Laws Really Matter." American Economic Review 96 (1): $152-75$.

Oreopoulos, Philip, Marianne E. Page, and Ann Huff Stevens. 2006. "The Intergenerational Effects of Compulsory Schooling." Journal of Labor Economics 24 (4): 729 60.

Parman, John. 2011. "American Mobility and the Expansion of Public Education." Journal of Economic Historv 71 (1): 105-32.

Pascarella, Ernest T., and Patrick T. Terenzini. 2005. How College Affects Students: A Third Decade of Research, vol. 2. San Francisco: Jossey-Bass.

Paterson, Lindsay, and Cristina Iannelli. 2007. "Social Class and Educational Attainment: A Comparative Study of England, Wales, and Scotland." Sociologv of Education 80 (4): 330-58.

Perkinson, Henry J. 1968. The Imperfect Panacea: American Faith in Education 18651965. New York: Random House. 


\section{American Journal of Sociology}

Perrin, John William. 1896. The History of Compulsory Education in New England. Meadville, Penn.: Flood \& Vincent.

Powell, Walter W., and Kaisa Snellman. 2004. "The Knowledge Economy." Annual Review of Sociology 30:199-220.

Powers, Daniel A., and Yu Xie. 2000. Statistical Methods for Categorical Data Analysis. New York: Academic Press.

Puerta, Juan Manuel. 2009. "'The Fewer, the Merrier': Compulsory Schooling Laws, Human Capital, and Fertility in the United States." Paper presented at Population Association of America annual meeting April 17, 2010, Dallas, Tex. http://paa2010 .princeton.edu/download.aspx?submissionId $=102057$.

Raftery, Adrian E. 1986. "Choosing Models for Cross-Classifications." American Sociological Review 51 (1): 145-46.

. 1995. "Bayesian Model Section in Social Research." Sociological Methodologv 25:111-63.

Raftery, Adrian, and Michael Hout. 1993. "Maximally Maintained Inequality: Expansion, Reform, and Opportunity in Irish Education, 1921-1975." Sociology of Education 66:41-62.

Rauscher, Emily. 2014. "Hidden Gains: Effects of Compulsory Schooling Laws on Attendance and Attainment by Social Background." Educational Evaluation and Policv Analvsis 36 (4): 501-18.

. 2015. "Educational Expansion and Occupational Change: U.S. Compulsory Schooling Laws and the Occupational Structure, 1850-1930." Social Forces 93 (4): 1397-1422.

Riley, Matilda White, Robert L. Kahn, and Anne Foner. 1994. Age and Structural Lag: Society's Failure to Provide Meaningful Opportunities in Work, Family, and Leisure. New York: Wiley.

Rubinson, Richard. 1987. "Class Formation, Politics and Institutions: Schooling in the United States.” American Journal of Sociology 92:519-48.

Ruggles, Steven. 2011. "Intergenerational Coresidence and Family Transitions in the United States, 1850-1880." Journal of Marriage and Family 73:136-48.

Ruggles, Steven, J. Trent Alexander, Katie Genadek, Ronald Goeken, Matthew B. Schroeder, and Matthew Sobek. 2010. Integrated Public Use Microdata Series: Version 5.0 [Machine-readable database]. University of Minnesota.

Sewell, William H., Archibald O. Haller, and Alejandro Portes. 1969. "The Educational and Early Occupational Attainment Process." American Sociological Review 34:8292.

Sorokin, Pitirim. 1959. Social and Cultural Mobility. New York: Free Press.

Steckel, Richard H. 1991. "The Quality of Census Data for Historical Inquiry: A Research Agenda." Social Science Historv 15 (4): 579-99.

Steffes, Tracy. 2012. School, Society, and State: A New Education to Govern Modern America, 1890-1940. Chicago: University of Chicago Press.

Steinhilber, August W., and Carl J. Sokolowski. 1966. State Law on Compulsory Attendance. U.S. Department of Health, Education, and Welfare, Office of Education, Circular 793. Washington, D.C.: General Printing Office.

Torche, Florencia. 2005. "Privatization Reform and Equality of Educational Opportunity in Chile." Sociology of Education 78 (4): 316-43.

. 2011. "Is a College Degree Still the Great Equalizer? Intergenerational Mobility across Levels of Schooling in the United States." American Journal of Sociologv 117 (3): 763-807.

Treiman, Donald J. 1970. "Industrialization and Social Stratification." In Social Stratification: Research and Theorv for the 1970s, edited by Edward O. Laumann, 207-34. New York: Bobbs-Merrill.

Tyack, David B. 1974. The One Best System: A History of American Urban Education. Cambridge, Mass.: Harvard University Press. 
Tyack, David B. 1976. "Ways of Seeing." Harvard Educational Review 43 (3): 355-89. U.S. Bureau of the Census. 1924. "School Attendance in 1920: An Analysis of School Attendance in the United States and in the Several States, with a Discussion of the Factors Involved." In Census Monographs V, by Frank Alexander Ross. Washington, D.C.: Government Printing Office. www2.census.gov/prod2/decennial/documents /04097225no5_TOC.pdf.

. 1975. Historical Statistics of the United States: Colonial Times to 1970. Washington, D.C.: General Printing Office. www.census.gov/prod/www/abs/statab.html.

U.S. Bureau of Education. 1914. Monthly Record of Current Educational Publications. Bulletin 572, no. 1.

van Leeuwen, Marco H. D., and Ineke Maas. 2010. "Historical Studies of Social Mobility and Stratification." Annual Review of Sociology 36:429-51.

Walters, Pamela Barnhouse. 2000. "The Limits of Growth: School Expansion and School Reform in Historical Perspective.” In Handbook of the Sociology of Education, edited by Maureen T. Hallinan. New York: Kluwer Academic/Plenum Publishers.

Weakliem, David L. 1999. "A Critique of the Bayesian Information Criterion for Model Selection.” Sociological Methods and Research 27 (3): 359-97.

Xie, Yu. 1992. "The Log-Multiplicative Layer Effect Model for Comparing Mobility Tables." American Sociological Review 57:380-95.

Xie, Yu, and Alexandra Achen Killewald. 2010. "Historical Trends in Social Mobility: Data, Methods, and Farming." PSC Research Report no. 10-716. www.psc.isr.umich .edu/pubs/pdf/rr10-716.pdf.

Zunz, Olivier. 1982. The Changing Face of Inequality: Urbanization, Industrial Development, and Immigrants in Detroit, 1880-1920. Chicago: University of Chicago Press. 